\title{
DENSITY DEPENDENCE IN AN ANNUAL PLANT COMMUNITY: VARIATION AMONG LIFE HISTORY STAGES
}

\author{
Deborah E. Goldberg, ${ }^{1,3,6}$ Roy Turkington, ${ }^{2}$ Linda Olsvig-Whittaker, ${ }^{3,4}$ And Andrew R. DyeR ${ }^{1,5}$ \\ ${ }^{1}$ Department of Biology, University of Michigan, Ann Arbor, Michigan 48109 USA \\ ${ }^{2}$ Department of Botany, University of British Columbia, Vancouver, British Columbia, Canada V6T 1Z4 \\ ${ }^{3}$ Mitrani Department for Desert Ecology, Blaustein Institute of Desert Research, Ben Gurion Campus 84990 Israel
}

\begin{abstract}
Most studies of density-dependent demography in plants consider the density only of the single focal species being studied. However, density-dependent regulation in plants may frequently occur at the level of the entire community, rather than only within particular species. In addition, because density dependence may differ considerably (even in direction) among demographic parameters, generalizing about patterns of density dependence and extrapolating to lifetime fitness and to population dynamics require comparisons among life history stages, as well as among types of species and physical environments.

We constructed seminatural communities of desert annuals composed of all the constituent species in the same relative proportions as found in the natural habitat. These experimental communities were planted at a range of densities that extended far above and below mean natural field density. We compared among physical environments (irrigation treatments), among communities from different physical environments, and among growth forms (dicot and graminoid) to search for generalizations about the magnitude and direction of density dependence.

Strong evidence of community-level density dependence was detected at all three life history stages studied in these desert annuals: emergence, survival, and final size. However, both the direction and degree of consistency of this density dependence varied considerably among the stages. The strongest and most consistent competitive effects were experienced at the emergence stage, where the mechanism is most likely a form of interference competition rather than exploitation competition. At the survival stage, the magnitude of effects was highly variable among physical environments and source communities, but negative effects were relatively rare, with either positive or no significant effects of increasing density. Thus, exploitation competition was also unimportant at the survival stage. In contrast, for growth, exploitation competition appeared to be the primary mechanism of interaction influencing growth. This variation in mechanism, direction, and magnitude of interactions among life history stages suggests that current models of plant community structure that are based largely on exploitation competition as it influences growth (with mortality a simple function of growth) are inadequate for even this simple annual plant community.

We also compared growth forms and found that graminoids were superior competitors to dicots at the emergence and survival stages; they also had higher emergence and survival, regardless of density. Consistent with this result, grasses are always the numerical dominants in the source communities. In contrast, the two growth forms did not differ in competitive ability for growth, and dicots were consistently larger individuals, independent of density, even though grasses were also usually the biomass dominants in the source communities. These results suggest the importance of nontrophic mechanisms of interaction in controlling community structure and again emphasize the importance of constructing and testing models that incorporate multiple mechanisms of interactions.
\end{abstract}

Key words: community-level density dependence; competition; demography; density dependence; desert annuals; facilitation; graminoid vs. dicot; life history; plants; population regulation.

\section{INTRODUCTION}

In Harper's (1967) classic “A Darwinian Approach to Plant Ecology," he emphasized the suitability of

Manuscript received 29 November 1999; revised 5 July 2000; accepted 31 July 2000; final version received 18 September 2000 .

${ }^{4}$ Current address: Science Division, Israel Nature and National Parks Protection Authority, 3 Am Veolami Street, Jerusalem 95463 Israel.

${ }^{5}$ Current address: Department of Biology and Geology, 471 University Parkway, University of South Carolina, Aiken, South Carolina 29208 USA.

${ }^{6}$ Corresponding author. E-mail: degold@umich.edu plants for demographic analysis. Since then, an immense research effort has been devoted to documenting and modeling demography of plant populations. However, not until relatively recently have attempts been made to synthesize this information quantitatively, by asking questions such as what life history stages are most important for population growth and how this varies among types of species and types of environments (e.g., Silvertown et al. 1993, 1996, Franco and Silvertown 1996). These attempts typically use elasticity analyses that are based on matrix models of exponential population growth (Caswell 1989), despite 
the fact that plant populations rarely if ever grow exponentially for very long. Instead, density is often an important influence on demographic parameters (e.g., Sarukhán and Harper 1973, Harper and White 1974, Law and Watkinson 1989, Crawley 1990, Watkinson 1997), although the magnitude and even direction (facilitation or competition) varies widely among studies. Thus, documenting and understanding patterns in population dynamics will necessarily involve documenting and understanding the sources of variation in density dependence of demographic parameters. Because different kinds of plants may be most strongly regulated at different life history stages, it is important to know whether density dependence tends to be stronger at particular life history stages or for particular demographic parameters, as well as whether such patterns are consistent among different types of species or environments. Unfortunately, despite the large literature on plant demography that has accumulated over the past $\sim 30 \mathrm{yr}$, information is rather sparse for addressing such general questions in plants for at least three reasons.

First, most studies of density-dependent demography in plants consider the density only of the single focal species being studied (e.g., Sarukhán and Harper 1973, Sarukhán 1974, Barkham 1980, Ford 1981, Smith 1983a, b, $c$, Shaw and Antonovics 1986, Ehrlen 1995a, $b$, Grace and Platt 1995, Watkinson 1997). Except in the relatively uncommon case of natural monocultures or near-monocultures, this approach ignores the density of many other potential competitors in the community and may well underestimate the amount of resource competition or other density-mediated interactions. We argue that density-dependent regulation in plants may frequently occur at the level of the entire community, rather than within particular species. This is because in communities that are close to biomass carrying capacity, low density of one species will be associated with higher density (or biomass) of other neighboring species that are likely to be potential competitors. Thus, studies of single species that ignore the density or presence of other species in the community may mask density-dependent demographic processes, even though they would be found if total plant density or biomass were measured. This notion is supported by the observation that removal of single species or even entire growth forms from a community often has relatively little effect on any of the remaining species (e.g., Putwain and Harper 1970, Allen and Forman 1976, Fowler 1981, Hils and Vankat 1982, Silander and Antonovics1982, Miller 1994), while removal of all possible neighbors typically has quite strong effects on growth of remaining target plants (Gurevitch et al. 1992, Goldberg et al. 1999).

A second cause of the difficulty of using existing literature to assess patterns in density dependence is that the great majority of demography studies that quantify density dependence in the field are nonex- perimental (but see Noble et al. [1979], Keddy [1981], Shaw [1987], Jonsdottir [1991], Fowler [1995], Watkinson [1997] for plant examples, and see Harrison and Cappuccino [1995] for a review of experimental studies on animals). Thus, effects of density variation (within species or overall) on individual fitness may often be confounded with effects of underlying environmental factors that may be associated with this density variation. This confounding can be avoided by using an experimental approach. While numerous field competition experiments have been conducted with plants, the great majority of these are not informative about patterns of density dependence for several reasons. Most importantly, field competition experiments in plants typically involve a simple comparison of performance of individuals in the absence of any vegetation vs. performance in the presence of natural vegetation (review in Goldberg and Barton [1992]). While this has the advantage of including all potential competitors, the existence of only two density values makes it impossible to extrapolate to other densities without assuming linearity of effects. Such linearity is apparently quite rare (review in Goldberg and Landa [1991]). Thus, sites or species cannot be compared directly, because any differences in the magnitude of density-dependent effects could be due either to differences in total density of competitors and/or to differences in per capita effects of competitors. In addition, most published field experiments on plant competition quantify competitive effects only at one or two life stages, even though density dependence may differ considerably (even in direction) among demographic parameters such as germination, survival growth, and reproduction (e.g., De Steven 1991a, b, Howard and Goldberg 2001). Thus, results of most studies cannot be easily extrapolated to lifetime fitness and to population dynamics (McPeek and Peckarsky 1998).

Third, both experimental and observational approaches to date have been used largely for a single or few species within a field study. Thus, even if results could be extrapolated to density-dependent effects on population dynamics for those species, we know little about how far we can extrapolate those results to other types of plants or environments.

In this study, we tried to avoid these limitations by quantifying the demographic responses of all individuals in diverse communities growing in different experimentally induced densities and environments. This permitted us to include all potential competitors for a large number of focal species, and, by monitoring plants from germination to maturity, we were able to investigate the demography of three important life stages of the component species. Specifically, we experimentally manipulated the density of entire communities of annual plants as well as irrigation levels, quantifying emergence, survival, and final size of all individuals in those communities. We used seed collected from three communities of annual plants from semistabilized 
sand dunes in Israel along a rainfall gradient in two different years. Each community was transplanted as seed bank at a range of densities to an experimental garden at an even drier site and subjected to a range of irrigation treatments to induce a productivity gradient. However, the disadvantage of attempting to monitor all individuals in diverse communities was that it was logistically impossible to record species identification of all seedlings ( $>40000$ in each year), as well as of questionable accuracy at the emergence stage for some groups such as grasses. Therefore, we report the density dependence of demographic data only for the two major divisions of dicots and monocots. Dyer et al. (2001) have shown that the grasses in this system differ substantially from dicots in a number of growth rate and morphological traits. We expected that these differences in traits would be reflected in differences in demography overall, as well as in demographic response to competition. For final biomass, species-specific responses to density were logistically possible to document; these responses and effects of density on overall species composition and diversity will be reported in subsequent papers. Here, we focus on the average response of individuals broadly representing each growth form in order to search for generalizations about density dependence at different life history stages. We asked the following specific questions:

1) Does the magnitude or direction of density dependence differ among the life history stages of emergence, survival, and growth? Are any patterns among stages consistent among growth forms, source communities, and/or abiotic environments (irrigation level)?

2) Does density dependence differ consistently between growth forms (i.e., are grasses consistently better or worse competitors than dicots), between abiotic environments (i.e., is competition consistently more intense at high productivity), or between source communities (i.e., is competition more intense in a community from a higher productivity environment)? Are any patterns consistent among life history stages?

A note on terminology. The terminology of density dependence has often been confused in the literature. As recommended by Crawley (1997), we also prefer the straightforward terminology of positive density dependence or facilitation for positive effects of increasing density (often called inverse density dependence, or "Allee effects"; Courchamp et al. 1999), and negative density dependence or competition (often called direct density dependence) for negative effects of increasing density. We use these terms throughout the rest of the paper.

\section{Methods \\ System}

Our experimental system consisted of annual plants occurring at three semistabilized sand dune sites in
Israel. Mean annual precipitation (MAP; 1951-1980 averages) ranges five-fold across the three sites, but is restricted to the winter in all sites, typically from midNovember to mid-April. In 1992-1993, we used a desert community (Holot Mashabim; $31^{\circ} 00^{\prime} \mathrm{N}, 34^{\circ} 44^{\prime} \mathrm{E}$; MAP, $110 \mathrm{~mm} / \mathrm{yr}$ ) and a semiarid community (Kerem Shalom; 31 ${ }^{\circ} 12^{\prime} \mathrm{N}, 34^{\circ} 18^{\prime} \mathrm{E}$; MAP, $190 \mathrm{~mm} / \mathrm{yr}$ ). The latter was replaced in the next year with a more mesic coastal community (Caesarea; 32 $30^{\prime} \mathrm{N}, 34^{\circ} 55^{\prime} \mathrm{E}$; MAP, $550 \mathrm{~mm} / \mathrm{yr}$ ) to make the comparison of source communities more extreme (Table 1). Each site is dominated by highly species-rich annual vegetation, and the desert and coastal sites were also interspersed with scattered shrubs. Common species in the desert source community include Ammochloa palaestina, Cutandia dichotoma, and Bromus fasciculatus (all Poaceae), Erodium laciniatum (Geraniaceae), Paronychia arabica (Caryophyllaceae) Filago spp (Asteraceae), Trifolium tomentosum (Fabaceae), and Matthiola livida and Erucaria pinnata (both Brassicaceae) (nomenclature follows Feinbrun-Dothan and Danin 1991). Common species in the coastal community include Aegilops sharonensis, Cutandia philistaea, and Brachypodium distachyon (all Poaceae), Rumex bucephalophorus (Polygonaceae), Plantago sarcophylla (Plantaginaceae), and Trifolium palaestina and Lotus halophilus (both Fabaceae). The semiarid (intermediate rainfall) community overlapped considerably with the more extreme sites. In addition to several species common to all three sites, overlap in generic composition was substantial in grasses (e.g., Aegilops, Bromus, Cutandia, Vulpia), legumes (e.g., Trifolium, Trigonella), and other dicots (e.g., Anthemis, Paronychia, Plantago, Rumex, Senecio) (D. E. Goldberg et al., unpublished data).

These annual sand dune assemblages have the advantage that entire communities are easily transplanted as seed banks. Thus, total community density can be manipulated by adding different amounts of wellmixed, concentrated (sieved) seed bank to a fixed area. This produces communities with initial densities ranging from below to above those naturally occurring densities, yet with constant initial relative densities of each species. The system also allowed us to harvest plants both above and below ground, and to obtain reasonable estimates of components of fitness within a single growing season. In both years, we quantified, by growth form (dicot and monocot), total emergence, final survival, and final size of all surviving individuals.

\section{Overview of experimental approach}

The basic experimental approach, called the "community-density experiment" (Goldberg et al. 1995, Goldberg and Estabrook 1998), is a simple extension of the single-species density-yield experiment (Harper 1977) to multispecies assemblages; the initial density of the entire community is manipulated, rather than the density of a single species. Seed banks were collected from the two source sites used in each year and trans- 
TABLE 1. Design of the community density experiments in two years.

\begin{tabular}{|c|c|c|}
\hline Design element & $1992-1993$ & 1993-1994 \\
\hline Source sites used & Desert and semiarid $\dagger$ & Desert and coastal \\
\hline \multicolumn{3}{|c|}{ Densities per source-irrigation combination according to plot size and no. replicates } \\
\hline $\begin{array}{ll}4 & 1-\mathrm{m}^{2} \text { replicates } \\
2 & 1-\mathrm{m}^{2} \text { replicates } \\
2 & 0.25-\mathrm{m}^{2} \text { replicates }\end{array}$ & $\begin{array}{l}1 / 16,1 / 8 \times \\
1 / 4,1 / 2,1 \times \\
2,4,8 \times\end{array}$ & $\begin{array}{l}1 / 16,1 / 8 \times \\
1 / 4,1 / 2,1 \times \\
1,2,4,8 \times\end{array}$ \\
\hline $\begin{array}{l}\text { Planting date } \\
\text { Germination census date } \\
\text { Harvest date }\end{array}$ & $\begin{array}{l}\text { 14-15 January } 1993 \\
\text { Cumulative over season } \\
\text { 19-22 April } 1993\end{array}$ & $\begin{array}{l}\text { 22-24 November } 1993 \\
18-25 \text { January } 1994 \\
18-21 \text { April } 1994\end{array}$ \\
\hline \multicolumn{3}{|l|}{ Total natural rainfall $(\mathrm{mm})$} \\
\hline $\begin{array}{l}\text { Garden } \\
\text { Desert } \\
\text { Semiarid } \\
\text { Coastal }\end{array}$ & $\begin{array}{r}56 \\
53 \\
250 \\
558\end{array}$ & $\begin{array}{r}58 \\
84 \\
123 \\
351\end{array}$ \\
\hline \multicolumn{3}{|c|}{ Additional rainfall in irrigation treatments $(\mathrm{mm}) \ddagger$} \\
\hline $\begin{array}{l}\text { Low } \\
\text { Intermediate } \\
\text { High }\end{array}$ & $\begin{array}{r}25(1.4 \times) \\
57(2.0 \times) \\
113(3.0 \times)\end{array}$ & $\begin{array}{r}43(1.7 \times) \\
163(3.8 \times) \\
302(6.2 \times)\end{array}$ \\
\hline
\end{tabular}

Notes: In both years, seed banks from two source sites were each planted in three irrigation regimes over the same range of densities, from $1 / 16$ of natural density to 8 times natural density. Replication was higher at the two lowest densities to compensate for the expected greater variation among plots. A smaller plot size was used for the highest densities to reduce the amount of seed bank to be collected from the source sites. In the second year, natural density plots were planted in both small and large plots to check for plot size effects. The target values for the ratios of total rainfall in each irrigation treatment (added, plus naturally occurring at the garden) to that naturally occurring in the garden are 1.1, 3.4, and 5.8 for the low, intermediate, and high irrigation treatments, respectively, based on the ratio of mean annual precipitation at the sites. Precipitation data are from the Israel Meteorological Service.

† The semiarid site had half as many replicates of each density in the intermediate irrigation treatment in 1992-1993.

\$ultiplicative factors in parentheses indicate the ratio of total rainfall in treatment to natural rainfall in the garden.

planted to a common experimental garden. Densities and productivity (through irrigation) of these transplanted communities were manipulated in a factorial experiment. To quantify competitive interactions, we used multiple densities with no or low replication for each density. Therefore, density effects were analyzed by regressions, and the magnitude of density effects was assessed among irrigation treatments and source communities by comparison of slopes of these regressions in analyses of covariance. This design and analytical approach has the advantage of allowing the shape of the relationship between performance and density to be determined; this relationship is rarely linear.

\section{The experimental garden}

To eliminate confounding by factors other than productivity, and to separate direct effects of the abiotic environment from effects of species assemblage, we transplanted seeds from source sites to an experimental garden at a site drier (MAP, $98 \mathrm{~mm} / \mathrm{yr}$ ) than either of the source sites and manipulated productivity by manipulating precipitation. Thus, we were able to test whether species assemblage, as well as environment (irrigation level), influences the magnitude of density dependence in these communities.

The experimental "sandbox" garden was constructed at the Blaustein Institute for Desert Research at Sde Boqer, $\left(30^{\circ} 48^{\prime} \mathrm{N}, 34^{\circ} 48^{\prime} \mathrm{E}\right)$ in the northern Negev Desert, $\sim 25 \mathrm{~km}$ southeast of the desert source site of Holot
Mashabim. The garden consists of 448 plots, arranged in 28 "trenches" of eight large $(1 \times 1 \mathrm{~m})$ and eight small $(0.50 \times 0.50 \mathrm{~m})$ plots each. Each $2 \times 10 \mathrm{~m}$ trench was dug to $1-\mathrm{m}$ depth, and then corrugated plastic liners were placed in the excavated area to separate the 16 plots in each trench from each other and from the surrounding loess soil. Each plot was then filled with sterile sand collected from $>10 \mathrm{~m}$ below the surface from a commercial quarry located in the same dune system as the Holot Mashabim source site. Before planting the second year's experiment, we removed the top $20 \mathrm{~cm}$ of sand from each plot and replaced it with freshly collected sterile sand. This removed any ungerminated seed bank or organic matter accumulated during the previous experiment.

We conducted the experiments in the garden rather than the field for several reasons: (1) because natural rainfall input is lower than even the desert source site, we can manipulate productivity by adding water rather than having to exclude rainfall; (2) because each plot is surrounded by a barrier of 1-m depth, soil resource availability is influenced only by plants rooted in that plot and whatever water is applied to that plot; (3) we have easy access to a water source for irrigation; and (4) we can control access to the plots by domesticated animals and curious humans.

\section{Seed bank collection, preparation, and planting}

At each of the two source sites used in each year, surface sand (depth, 0-2 cm) was collected in Septem- 
ber each year, after the dry summer and one to two months before the beginning of the next rainy season and subsequent germination. In 1992-1993, seed bank was collected with shovels skimming the surface from $\geq 60$ locations at each site. The locations were randomly chosen with the constraint that they were $\geq 30 \mathrm{~cm}$ from the canopy edge of any shrubs. In 1993-1994, seed bank was collected with a skimmer designed to sample the top $2 \mathrm{~cm}$ more precisely. The skimmer was dragged along three 50-m transects established from randomly located starting points with randomly chosen directions within each source site. Samples were taken continuously along the transects, with the constraint of maintaining $\geq 30 \mathrm{~cm}$ margin from the edge of shrubs. In both years, the samples from within each source site were combined, and all material that passed through a fine sieve $(350 \mu$ mesh size in year $1 ; 500 \mu$ mesh size in year 2) was discarded. We tested germination in the discarded material and found almost no seedling emergence after irrigation, indicating the sieving method successfully separated the seed bank from the sand substrate. All material that did not pass through the fine sieve was used as the desert and semiarid seed bank. However, the coastal samples had many more large fragments of old stems, leaves, and flower parts. We therefore passed the coastal samples through a $2000 \mu$ mesh sieve; pieces of inflorescences still attached were stripped and rubbed gently against the sieve to dislodge individual propagules. All material not passing through this coarse sieve was also discarded. The remaining material was combined for each source, thoroughly mixed, and used as the concentrated seed bank. The seed bank from all sources contained some organic matter that could not be separated from the seed bank; this amount was not quantified, but was correlated with rainfall of the source sites: greatest in the coastal site and lowest in the desert site.

A gradient in initial community density (ICD) was established by sowing different amounts of this concentrated seed bank to the surface of standard size plots. This allowed us to change the seed density while keeping the initial relative abundances of species constant. A geometric series of eight densities was used in each year: $1 / 16,1 / 8,1 / 4,1 / 2,1,2,4$, and 8 times the mean natural field density. To determine planting amounts, rather than actually counting seeds, we assumed that an amount of seed bank equal to the mean mass of seed bank collected per square meter would contain the mean density of seeds found per square meter in the field. The use of a geometric density series ensured that most of the ICD values were relatively low, allowing us to identify the densities at which important interactions began to appear. In both years, the seed bank was spread uniformly across the surface of the sand of each plot and then covered by $1 \mathrm{~cm}$ of sterile sand and lightly watered with an equivalent of $5 \mathrm{~mm}$ of rainfall to prevent loss of seed bank by wind movement. This initial watering was too small to trigger any germination.

\section{Irrigation treatments}

The three irrigation treatments in both years mimicked aspects of the precipitation regimes of the two extreme source sites as well as an intermediate regime. In 1992-1993, water was applied as a fine spray from a handheld hose for each plot, keeping track of amounts applied to each plot by a flow meter. In 1993-1994, a computer-controlled sprinkler system was installed and programmed to give the appropriate amounts of water for each irrigation event separately. Long-term rainfall records indicate that, on average, the desert and coastal sites receive, respectively, 1.1 and 5.8 times the annual precipitation of the garden site at Sde Boqer. After each naturally occurring rainfall event at Sde Boqer, additional water was supplied to each irrigation treatment to maintain these proportional differences, with the intermediate treatment receiving the midpoint of these extremes (3.45 times precipitation at Sde Boqer). In addition, if no rain fell at the garden site for a period of two weeks, each of the treatments was irrigated with the equivalent of $1 / 12$ of the mean annual precipitation for the desert site (low treatment), coastal site (high treatment), or the midpoint (intermediate treatment). The growing season lasts $\sim 24 \mathrm{wk}$, so this regime would result in exactly the mean annual amounts of precipitation from the source sites being applied to each treatment, if no rainfall occurred at Sde Boqer. The actual amounts of water added in each year deviated considerably from the observed proportional differences among sites, however, because of vagaries of weather and logistics (Table 1). In year 1, the ratios were mostly lower than these target amounts, because $40 \%$ of the total annual rainfall that year fell before we planted the experiment and began irrigation treatments (we nevertheless include the rainfall in the amount experienced by the plants because much of it would be expected to drain into the sand and be stored in subsurface layers for later plant use). In year 2, the ratios were higher than the target amounts, because of the biweekly irrigation events in the absence of natural rainfall.

Precipitation in Israel is usually related to large fronts that approach from the west, such that rainfall events at our three source sites and the garden site are correlated in time, although increasingly frequent from the desert to the coastal site. Therefore, using the naturally occurring rainfall at Sde Boqer in a given year as a basis for the experimental treatments has the advantage of maintaining differences in total amount of water among treatments that are relevant to the source sites. Unfortunately, it was logistically impossible to also mimic the frequency component of the natural rainfall regimes. Nevertheless, frequency of rainfall and, particularly, the duration of intervals between rain pulses is an important part of rainfall regimes in dry lands (Noy-Meir 1973, Goldberg and Novoplansky 
1997), and this should be kept in mind when interpreting results.

\section{Experimental design}

In the first year, we used a factorial design of two source communities (desert and semiarid) $\times$ three irrigation treatments $\times$ eight ICD values, each replicated two or four times (Table 1). Replication was higher at the two lowest densities to compensate for the expected greater variation among plots because of the fewer number of plants per plot; number of experimental plots totaled 110 , with 77 measuring $1 \mathrm{~m}^{2}$ and 33 measuring $0.25 \mathrm{~m}^{2}$. In each trench, we also had two "control" plots (one large and one small) with no seed bank added, to test for immigration of seeds from outside the experimental plots; germination in these plots was minimal, thus we do not discuss them further. To produce enough seed bank for the three highest densities (2, 4, and $8 \times$, respectively) in $1-\mathrm{m}^{2}$ plots would have required enormous volumes of unsifted sand (field seed bank collections). Therefore, these highest seed bank densities were planted into the $0.25-\mathrm{m}^{2}$ plots; all other ICDs were planted in the $1-\mathrm{m}^{2}$ plots. In the second year, we used a similar design, except that we used the coastal source site instead of the semiarid site and that the natural densities were planted in both large $\left(1-\mathrm{m}^{2}\right)$ and small $\left(0.25-\mathrm{m}^{2}\right)$ plots, for a total of 132 plots (Table 1).

The use of a regression design with multiple densities with no or low replication, rather than the more typical comparison of a few, well-replicated mean values in ecological field experiments, combined with the relatively small size of the trenches, made it impossible to lay out the design as a formal randomized block design. In addition, physical constraints forbade the application of more than one irrigation treatment to a trench. Instead, we put one full set of replicates of all treatments in a group in each of two rows of trenches in an attempt to reduce any bias due to consistent environmental differences between rows of trenches.

\section{Monitoring}

Each plot had a $10-\mathrm{cm}$ buffer zone in which we did not monitor or harvest plants. Therefore, effective plot sizes were $80 \times 80 \mathrm{~cm}$ and $30 \times 30 \mathrm{~cm}$ for large and small plots, respectively. Monitoring procedures differed between the two years.

In 1992-1993, we censused all plots on six occasions to determine the total number of emerging seedlings. All plots were divided into four subplots, and we did detailed monitoring in the number of subplots required to give $\geq 50$ censused plants per plot. At each census, we marked all new individuals with color-coded (by cohort) toothpicks placed, and we recorded their growth form (grass or dicot). The sum of emerging seedlings over all censuses was used to estimate germination in each plot.

In 1993-1994, we used a similar procedure in only a subset of the plots $(1 / 16,1$, and 4 times initial densities for each irrigation-source combination in only one of the blocks; $n=18$ plots), in an effort to reduce the need to individually mark such large numbers of seedlings. These plots were monitored for new seedlings and mortality on a weekly basis after planting. By mid-January, emergence appeared to be largely completed (very few new seedlings appearing), but mortality was still low. Therefore on 18-25 January 1994, we counted seedlings (as graminoids or dicots) in all plots in the experiment to estimate total emergence. Based on subsequent counts in these plots, $99 \%$ of the total cumulative emergence had occurred before the January seedling census, but only $7 \%$ of these emergents died before the January main seedling census. Cumulative mortality more than doubled (to $15 \%$ of the original emergents) in the two weeks following the January main seedling census. The precount mortality means that the 1994 emergence rates are likely to be slight underestimations, and survival rates are likely to be slight overestimations, relative to year 1 results.

\section{Harvesting}

Harvesting took place in mid-April of both years, after cessation of natural rainfall, and as most species were just beginning to dry after ripening seeds (Table 1). Because of differences among species in timing of seed production and release, as well as the large numbers of plants, it was impossible to collect seed output. Instead, we use final size per plant as a surrogate for reproduction; seed production is typically highly correlated with biomass in annual plants (e.g., Miller 1987). In both years, we harvested all aboveground biomass, including loose material (mostly dispersed seed and senesced plant parts) found on the plot surface. All harvested material was placed in a freezer, where the low water content of the plants kept the material in excellent condition until each bag could be unfrozen, sorted to species (including the loose material), roots and shoots separated, and individuals per species counted, dried, and masses measured.

\section{Statistical analyses}

All analyses were conducted with SYSTAT Version 7.0 for Windows (SPSS 1997). Data were always analyzed separately for the two years because of the difference in the higher productivity source community used between years, as well as for the three demographic stages because of differences in the measure of density used to quantify potential competition intensity. Thus, most of the analyses that we describe were repeated for each of these six stage-year combinations. Although we did not use Bonferroni adjustments for significance across these six combinations, because of the multiple analyses and multiple factors in each analysis, our general philosophy of interpretation was to look for consistency of patterns of results (both in terms of actual magnitudes and of significance 
levels), rather than to focus in detail on which results were significant at the arbitrary level of 0.05 (StewartOaten 1995, Osenberg et al. 1999). We restrict discussion largely to highly significant $(P<0.001)$ patterns, or to those that are consistent across multiple treatment combinations, even if not highly significant within each combination.

Effectiveness of the irrigation treatments.-The effectiveness of the irrigation treatments was assessed by comparing final standing crop among the irrigation treatments and source communities in each year with two-way ANOVAs.

Demography.-Effects of density and the other treatments on demography could be assessed either on population size at each stage or on individual performance at each stage. These two approaches have quite different null hypotheses and require quite different statistical analyses. For population size analyses, the biological null hypotheses is that the number of emerging seedlings per plot increases linearly with number of seeds planted per plot, number of surviving plants increases linearly with number of emergents, and final biomass per plot increases linearly with number of survivors. Nonlinearity of these relationships would indicate density dependence, with concave shapes indicating competition and convex shapes indicating facilitation. For individual performance analyses, the biological null hypotheses is that per-seed probability of emergence, survival probability, and mass per plant are all independent of density, i.e., have slopes of zero when regressed against the appropriate measure of density. Significant negative slopes indicate negative density dependence (competition) and significant positive slopes indicate positive density dependence (facilitation).

We chose to use the individual performance-analytical approach in this paper for two reasons. First, the biological null hypothesis and the standard statistical null hypothesis are congruent in this case (i.e., no relationship between individual performance and density). Second, density dependence could be revealed in this case through linear relationships (or by relationships that could be linearized through transformations) rather than being demonstrated only by significantly nonlinear relationships. Thus standard statistics such as ANCOVA can be used to compare the magnitude of density dependence by comparing slopes. Superficially, it may appear that this approach will introduce spurious relationships, because the relationships are of the form $y / x$ vs. $x$ (i.e., one expects that, by chance, as $x$ [density] increases, $y / x$ [individual performance] will decrease). However, this expectation assumes that $y$ and $x$ are randomly associated. As described, the biological null hypothesis for the population size analytical approach is that $y$ (e.g., total final density) and $x$ (e.g., total initial density) are linearly positively correlated, rather than unrelated. If this biological null hy- pothesis holds, $y / x$ and $x$ are necessarily not correlated, i.e., the typical statistical null hypothesis of no relationship is restored for analyses of per capita response to density, and no spurious correlations are expected.

The basic design was a four-way ANCOVA, with a measure of community density as a covariate, and source community (desert and semiarid or coastal), growth form (dicot or graminoid), and irrigation (low, intermediate, high) as categorical factors. We analyzed the effect of these four factors on three different response variables describing individual performance, corresponding to three life history stages. In all cases, the response variable was calculated separately for dicots and graminoids within each plot. For the emergence stage, we calculated an index of the probability that an individual seed would emerge above ground as follows: number of emerged seedlings per initial community density (ICD), where ICD is the relative seed bank density from $1 / 16$ of natural density to eight times natural density. Number of emerged seedlings was the cumulative number of new seedlings (those observed over all the censuses in year 1 , or the number of seedlings counted in the January seedling census in year 2). Survival was calculated as follows: number of seedlings in a plot surviving to the end of the growing season per number of emerged seedlings in that plot. Final size was calculated as the total biomass of plants in a plot per number of surviving plants in the plot.

The appropriate measure to use as a covariate to assess density effects depended on the life history stage. For emergence, the appropriate density measure was the planting density, expressed as a fraction of natural seed bank (from 1/16 of natural to eight times natural). For survival, the appropriate density measure was density of emerging seedlings. This was expressed as the cumulative emergence over the entire season for year 1 and as the total number of seedlings found at the emergence census in January in year 2. For final mass, the appropriate density measure was final density of surviving plants to the end of the season; this excluded plants that died before or during the peak period of growth during the relatively warm months of March and early April. Use of different measures of density, e.g., relative planting density for survival or growth, gave similar results for each stage (D. E. Goldberg et al., unpublished data).

Four transformations were tried in an attempt to linearize the performance-density relationships, so that slopes could be compared among the experimental factors with ANCOVA. To find the best fit, we compared the following functions for each of the three measures of individual performance, respectively, for each of the combinations of source community, growth form, and irrigation treatment in each year; where $p$ is individual performance measure, $d$ is density measure, and $a$ and $b$ are fitted parameters: 


$$
\begin{aligned}
& \text { Linear: } & p & =a+b d \\
& \text { Power: } & \ln (p) & =a+b \ln (d) \\
& \text { Semilog: } & p & =a+b \ln (d) \\
& \text { Reciprocal: } & 1 / p & =a+b d .
\end{aligned}
$$

For emergence and growth in both years, a log-log transformation (power model) fit the data best both in terms of higher $r^{2}$ and more normally distributed residuals (D. E. Goldberg et al., unpublished data). For survival, a linear model fit the data best in year 2, and a semilog model fit the data best in year 1. Surprisingly, the reciprocal model was very rarely a good fit, even though it, or its variations, has become the more or less standard model for population dynamics of annual plants (Watkinson 1980).

In the ANCOVAs, significant main effects were interpreted as differences among factor levels that were independent of density, while interactions involving density (the covariate) and one or more of the other factors were regarded as testing variation in the magnitude of density dependence. Significant interactions indicate that slopes (i.e., per capita effects) differ between treatments.

\section{RESULTS}

\section{Irrigation treatments and productivity}

In both years, irrigation significantly increased aboveground standing crop (Table 2, Fig. 1). The source communities also differed in both years, although in different directions (Table 2, Fig. 1). In year 1, the desert community had a slightly higher standing crop than the semiarid source community; this was apparent at low and intermediate levels of irrigation, but not at high irrigation (Fig. 1). In contrast, in year 2 when the two experimental communities were from more extreme points along the natural rainfall gradient, the desert had less standing crop than the coastal com-

TABLE 2. Summary of ANOVA for total aboveground final standing crop in both years of the experiment.

\begin{tabular}{lrrrrrr}
\hline \hline & & \multicolumn{2}{c}{$1992-1993$} & & \multicolumn{2}{c}{$1993-1994$} \\
\cline { 3 - 4 } \cline { 5 - 6 } \multicolumn{1}{c}{ Source } & df & $F$ & $P$ & & $F$ & $P$ \\
\hline Source community & 1 & 3.690 & 0.074 & & 15.807 & 0.001 \\
Irrigation & 2 & 3.699 & 0.049 & & 23.551 & 0.000 \\
Community $\times$ & 2 & 0.327 & 0.726 & & 3.878 & 0.044 \\
$\quad$ Irrigation & 15 & & & & \\
Error & & & & &
\end{tabular}

Notes: The two source communities were a desert and a semiarid site in 1992-1993 and a desert and a coastal site in 1993-1994. Irrigation treatments in both years mimicked the desert source, the coastal site, and an intermediate regime (see Table 1 for source site descriptions). Only data from the higher densities (greater than natural density) were used in the analysis, because yield no longer increased with density among these samples in most of the source-irrigation combinations. Standing crop data were natural-log-transformed prior to analysis (untransformed data shown in Fig. 1). Two extreme outliers were deleted from the 1993-1994 data. a) 1992-1993 growing season

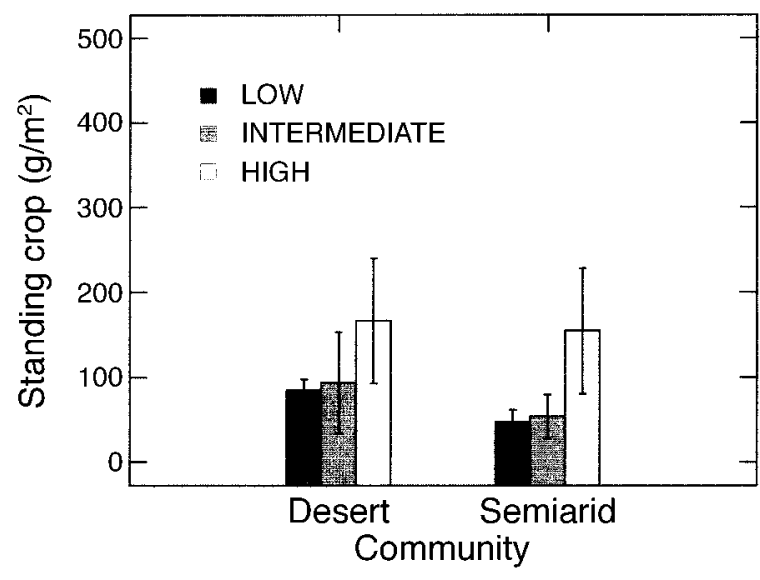

b) 1993-1994 growing season

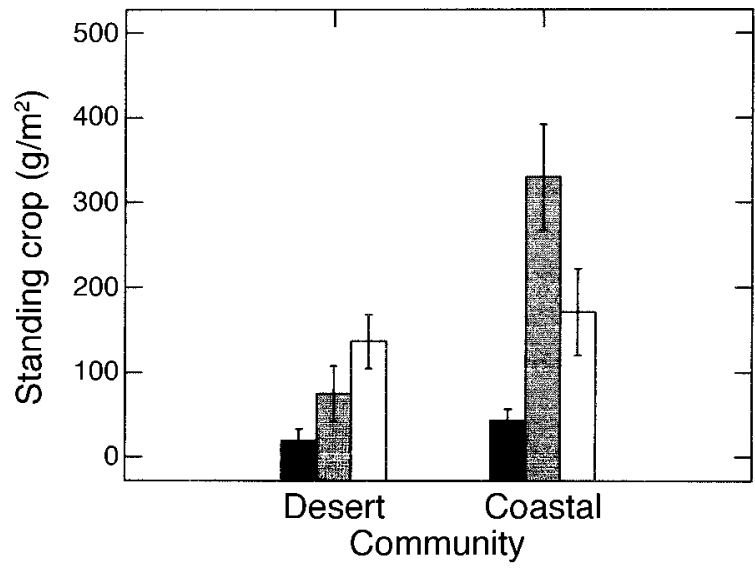

FIG. 1. Mean ( \pm 1 SE) aboveground standing crop for three source communities transplanted to a desert experimental garden under different irrigation regimes in two years: (a) 1992-1993 (year 1) and (b) 1993-1994 (year 2). See Table 1 for descriptions of source communities and irrigation regimes. Only plots planted at high seed bank density (2, 4, and 8 times natural seed bank density) were included ( $n=6$ for each value), because total biomass per plot was density independent for this range of planting density. ANOVA results for these data are in Table 2.

munity, especially at the intermediate irrigation (Fig. 1 ), resulting in a highly significant interaction between source community and irrigation treatment (Table 2). The reason for the decline in standing crop in response to the highest irrigation in this community is not clear.

\section{Probability of emergence}

In both years, regressions of the emergence probability index on initial community density (relative seed bank density) were strongly negative and nonlinear for all 12 combinations of growth form, source community, and irrigation treatment (Figs. 2 and 3, Table 3). The magnitude of this negative density dependence was 
1992-1993 growing season
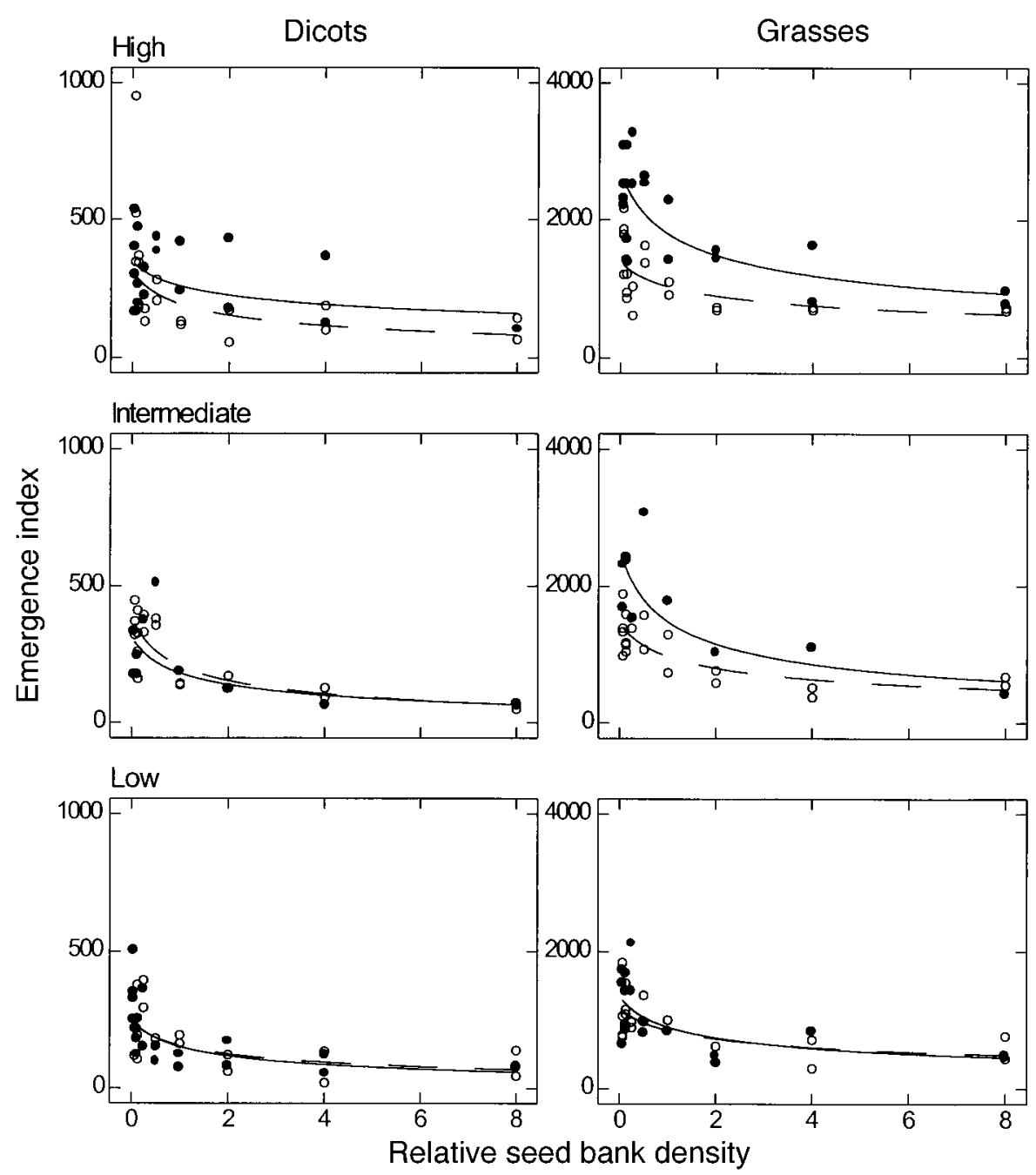

FIG. 2. The effect of initial community density on an index of the probability of an individual seed emerging for dicots and grasses of two source communities (desert, solid lines and filled circles; semiarid, dashed lines and open circles) under three irrigation regimes (high, intermediate, and low) in the first year of the experiment. Initial community density is expressed as the density of seed bank planted relative to the natural seed bank density and ranges from 1/16 to 8 times natural density. The emergence index is calculated as the cumulative number of seedlings emerging in a plot over the entire growing season divided by the initial community density. Curves represent power function fits to the data where $P<0.10$. ANCOVAs of these data (using natural $\log -\log$ transformations) are shown in Table 4; regression equations using the transformed data are in Table 3.

largely similar among treatments; initial density was involved in only one significant interaction out of 14 possible interactions involving density (Table 4). In year 2, emergence of dicots were more strongly inhibited by increasing density than were grasses, i.e., dicots were poorer response competitors (steeper slopes for dicots in Fig. 3, Table 3; significant form $\times$ density interaction in Table 4). A similar, but weaker trend $(P$ $=0.071$ ) was seen in Year 1 (Fig. 2, Table 4). Dicots also had lower overall emergence in all irrigationsource combinations in both years (significant main effects in Table 4; note lower regression intercepts in
Figs. 2 and 3, Table 3). Although there were no differences in the magnitude of density dependence between the source communities or among irrigation treatments (no significant interactions of source community or irrigation with density in Table 4), their main effects were highly significant in three out of four cases, and they significantly interacted with each other in both years (Table 4). Specifically, germination tended to be higher overall in the desert community (especially for grasses and at high irrigation) and to increase with increasing irrigation (especially in the desert community) (Figs. 2 and 3, Table 3). 
1993-1994 growing season
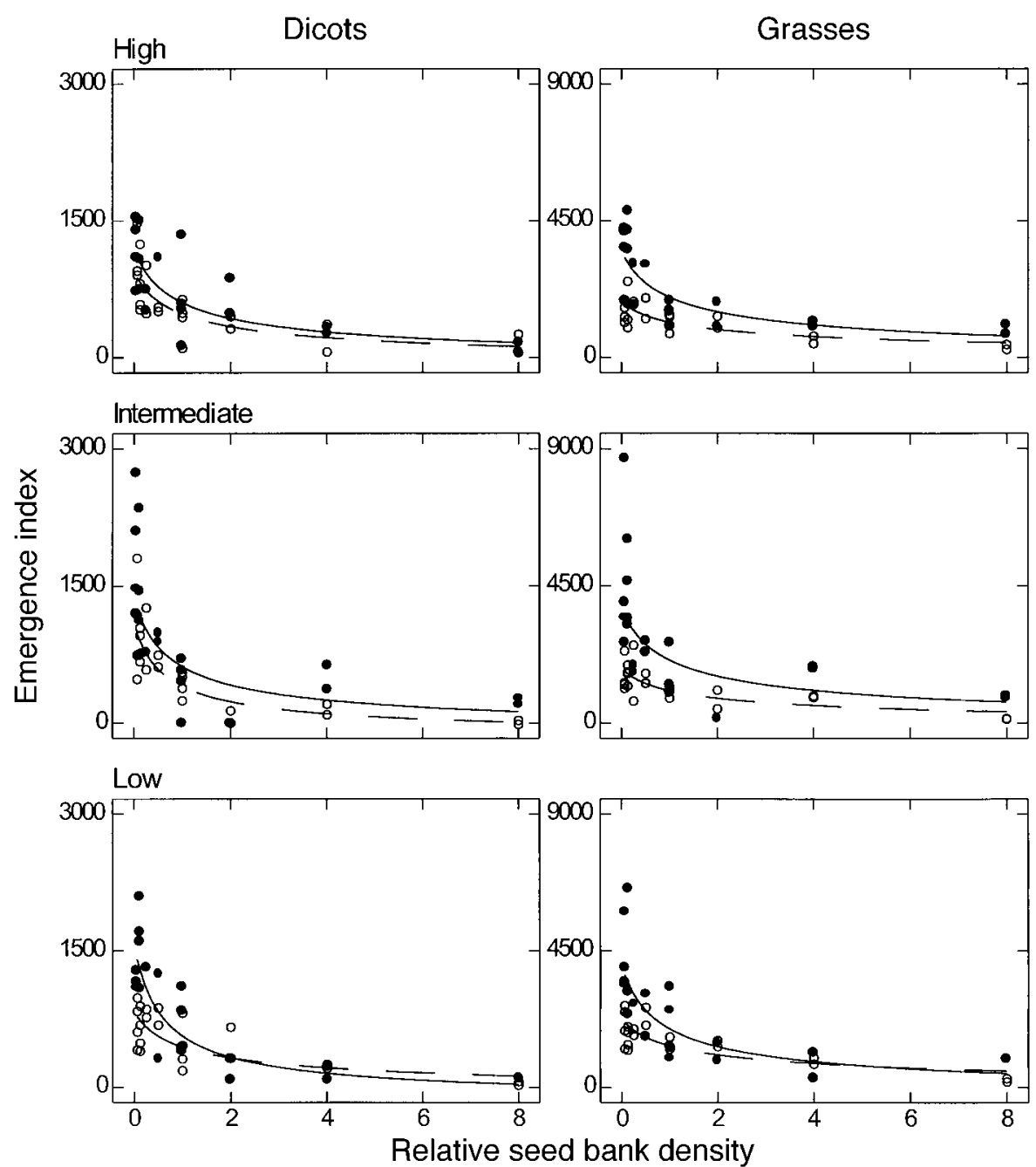

FIG. 3. The effect of initial community density on an index of the probability of an individual seed emerging for dicots and grasses of two source communities (desert, solid lines and filled circles; coastal, dashed lines and open circles) under three irrigation regimes (high, intermediate, and low) in the second year of the experiment. See also Fig. 2 legend.

\section{Probability of survival}

Unlike the strong and consistent negative effects on emergence, effects of density on survival tended to be either mostly facilitative (1992-1993; Fig. 4, Table 5), or mostly nonexistent (1993-1994; Fig. 5, Table 5). As with emergence, dicots seem to be poorer competitors in terms of survival response to density. In year 1, grasses in both source communities consistently showed strong facilitative responses to increasing density, while dicots in one community showed fewer significant positive responses to density (Fig. 4, Table 5; significant community $\times$ growth form $\times$ density interaction and marginal form $\times$ density interaction $[P$ $=0.08$ ] in Table 4 ). In year 2 , fewer effects of density were significant within treatment combinations, but those that existed were competitive for dicots and facilitative for grasses (Fig. 5, Table 5), resulting in a highly significant $(P=0.001)$ form $\times$ density interaction (Table 4). Growth forms also differed overall in year 1, but not year 2 (main form effect in Table 4), with dicots having higher overall survival than grasses (Figs. 4 and 5, Table 5).

In addition, the magnitude of density dependence significantly interacted with irrigation in year 2 (Table 4), although no clear pattern is apparent in Fig. 5: the single facilitative effect was at high irrigation (grasses from the coastal community), while the two significant competitive effects were at low and intermediate irrigation (dicots from the coastal and desert communities, respectively).

As with emergence, source communities and irrigation levels had strong effects on the overall level of survival, despite their lack of effect on the magnitude of density dependence. In both years, survival was low- 
TABLE 3. Coefficients for log-log regressions of the individual emergence index on initial community density, for each combination of year, source community, growth form, and irrigation treatment.

\begin{tabular}{|c|c|c|c|c|c|c|}
\hline Irrigation & Form & $\mathrm{df}$ & Intercept & Slope & $R$ & $P$ \\
\hline \multicolumn{7}{|c|}{ 1992-1993 Growing season } \\
\hline \multicolumn{7}{|c|}{ Desert community } \\
\hline High & dicot & 18 & 5.477 & $-\mathbf{0 . 1 3 3}$ & 0.45 & 0.047 \\
\hline High & grass & 18 & 7.395 & -0.193 & 0.76 & 0.000 \\
\hline Intermediate & dicot & 8 & 5.038 & -0.263 & 0.68 & 0.029 \\
\hline Intermediate & grass & 8 & 7.169 & -0.252 & 0.77 & 0.009 \\
\hline Low & dicot & 18 & 4.835 & -0.292 & 0.81 & 0.000 \\
\hline Low & grass & 18 & 6.688 & -0.206 & 0.71 & 0.000 \\
\hline \multicolumn{7}{|c|}{ Semiarid community } \\
\hline High & dicot & 18 & 5.088 & -0.271 & 0.71 & 0.000 \\
\hline High & grass & 18 & 6.851 & -0.159 & 0.72 & 0.000 \\
\hline Intermediate & dicot & 18 & 5.144 & -0.325 & 0.87 & 0.000 \\
\hline Intermediate & grass & 18 & 6.773 & -0.204 & 0.80 & 0.000 \\
\hline Low & dicot & 18 & 4.875 & -0.251 & 0.62 & 0.005 \\
\hline Low & grass & 18 & 6.654 & -0.166 & 0.65 & 0.002 \\
\hline \multicolumn{7}{|c|}{ 1993-1994 Growing season } \\
\hline \multicolumn{7}{|c|}{ Desert community } \\
\hline High & dicot & 18 & 6.135 & -0.384 & 0.75 & 0.000 \\
\hline High & grass & 18 & 7.422 & $-\mathbf{0 . 3 0 0}$ & 0.86 & 0.000 \\
\hline Intermediate & dicot & 17 & 6.418 & -0.367 & 0.89 & 0.000 \\
\hline Intermediate & grass & 19 & 7.404 & -0.349 & 0.70 & 0.000 \\
\hline Low & dicot & 18 & 5.981 & -0.552 & 0.84 & 0.000 \\
\hline Low & grass & 18 & 7.360 & $-\mathbf{0 . 3 7 7}$ & 0.82 & 0.000 \\
\hline \multicolumn{7}{|c|}{ Coastal community } \\
\hline High & dicot & 20 & 5.893 & -0.403 & 0.79 & 0.000 \\
\hline High & grass & 20 & 6.910 & -0.241 & 0.75 & 0.000 \\
\hline Intermediate & dicot & 19 & 5.576 & -0.583 & 0.78 & 0.000 \\
\hline Intermediate & grass & 20 & 6.772 & -0.300 & 0.73 & 0.000 \\
\hline Low & dicot & 20 & 5.831 & -0.366 & 0.72 & 0.000 \\
\hline Low & grass & 20 & 7.060 & -0.266 & 0.72 & 0.000 \\
\hline
\end{tabular}

Notes: Untransformed data are shown with power fits in Figs. 2 and 3, and ANCOVAs comparing slopes on density among treatments are in Table 4. Significant $(P<0.05)$ regressions are shown in bold.

TABle 4. $P$ values from ANCOVAs for demographic parameters using plot means for both years of the experiment.

\begin{tabular}{|c|c|c|c|c|c|c|c|}
\hline \multirow[b]{2}{*}{ Factor } & \multirow[b]{2}{*}{ df } & \multicolumn{2}{|c|}{ Emergence } & \multicolumn{2}{|c|}{ Survival } & \multicolumn{2}{|c|}{ Mass/plant } \\
\hline & & Year 1 & Year 2 & Year 1 & Year 2 & Year 1 & Year 2 \\
\hline Source community & 1 & 0.001 & 0.000 & 0.000 & 0.249 & 0.000 & 0.203 \\
\hline Form & 1 & 0.000 & 0.000 & 0.004 & 0.297 & 0.023 & 0.000 \\
\hline Irrigation & 2 & 0.000 & 0.855 & 0.000 & 0.621 & 0.000 & 0.203 \\
\hline Density & 1 & 0.000 & 0.000 & 0.000 & 0.073 & 0.000 & 0.000 \\
\hline Source $\times$ Density & 1 & 0.852 & 0.483 & 0.901 & 0.248 & 0.000 & 0.458 \\
\hline Form $\times$ Density & 1 & 0.071 & 0.001 & 0.080 & 0.001 & 0.594 & 0.075 \\
\hline Irrigation $\times$ Density & 2 & 0.213 & 0.332 & 0.208 & 0.005 & 0.001 & 0.034 \\
\hline Irrigation $\times$ Form $\times$ Density & 2 & 0.717 & 0.962 & 0.155 & 0.581 & 0.194 & 0.022 \\
\hline Irrigation $\times$ Source $\times$ Density & 2 & 0.460 & 0.071 & 0.629 & 0.064 & 0.690 & 0.018 \\
\hline Community $\times$ Form $\times$ Density & 1 & 0.156 & 0.271 & 0.023 & 0.174 & 0.024 & 0.175 \\
\hline Irrigation $\times$ Source $\times$ Form $\times$ Density & 2 & 0.506 & 0.239 & 0.557 & 0.278 & 0.843 & 0.188 \\
\hline Source $\times$ Irrigation & 2 & 0.002 & 0.013 & 0.055 & 0.010 & 0.981 & 0.023 \\
\hline Source $\times$ Form & 1 & 0.042 & 0.624 & 0.000 & 0.000 & 0.533 & 0.726 \\
\hline Irrigation $\times$ Form & 2 & 0.914 & 0.461 & 0.122 & 0.629 & 0.175 & 0.017 \\
\hline Source $\times$ Irrigation $\times$ Form & 2 & 0.344 & 0.362 & 0.507 & 0.127 & 0.778 & 0.174 \\
\hline Error df & & 195 & 227 & 192 & 227 & 191 & 231 \\
\hline
\end{tabular}

Notes: Source community, growth form (dicot or monocot), and irrigation were treated as fixed factors, and a measure of density was used as a covariate for each analysis. The measure of density depended on the response variable: for emergence, density tests the effect of relative seed bank density (from 1/16 of natural to 8 times natural density); for survival, density tests the effect of cumulative number of emerging seedlings in the plot; and for growth, density tests the effect of the final number of surviving seedlings on final size. For emergence probability and mass per plant, both the response variable and the density variable were natural-log-transformed in both years. For survival, only the density measure was natural-logtransformed in year 1 , and neither survival probability nor the density measure was transformed in year 2 . Significant $(P<$ $0.05)$ effects are shown in bold, and nonsignificant trends $(P<0.10)$ are shown in italics. 


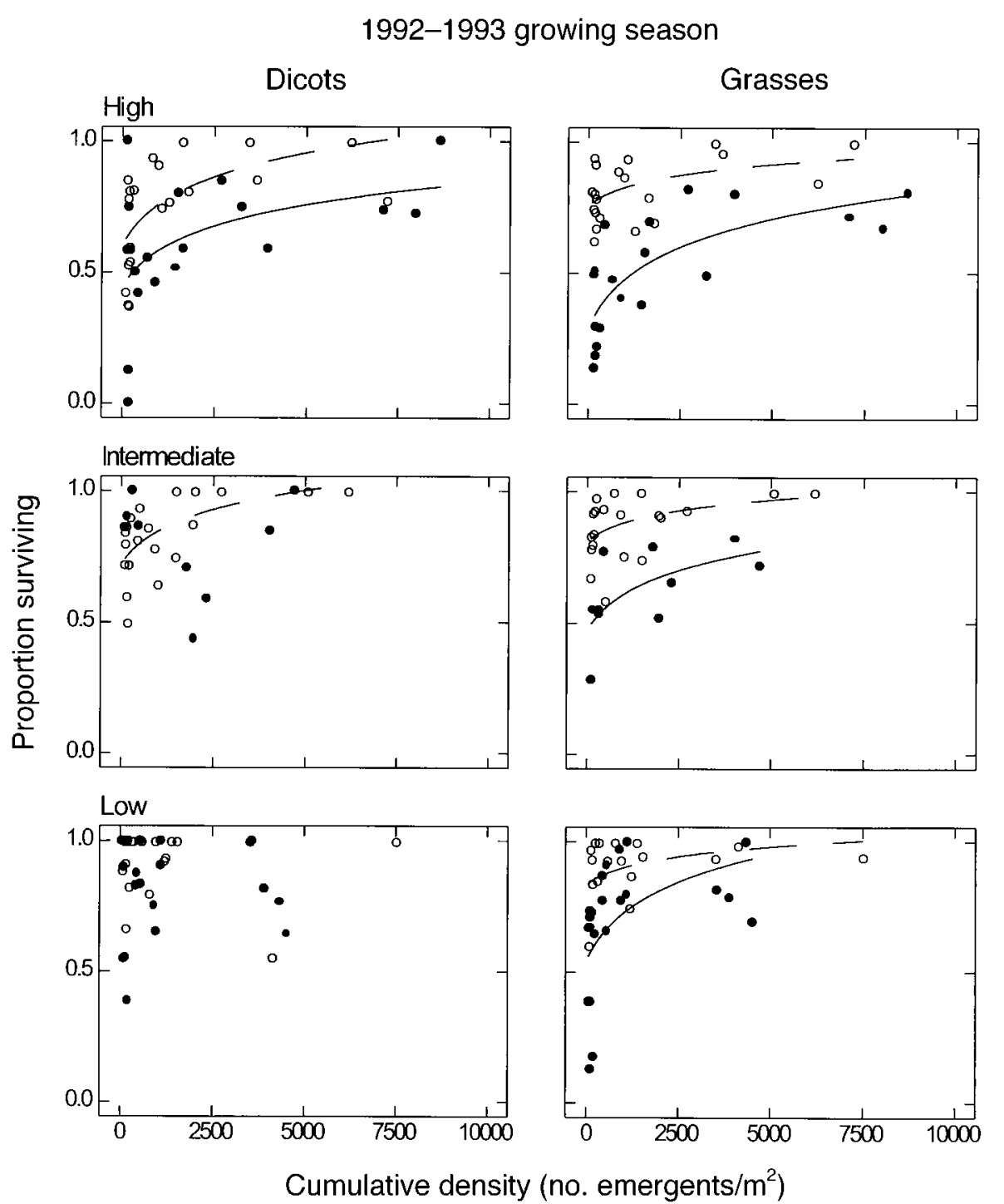

FIG. 4. The effect of density of emerging seedlings on survival to the end of the growing season for dicots and grasses of two source communities (desert, solid lines and filled circles; semiarid, dashed lines and open circles) under three irrigation regimes (high, intermediate, and low) in the first year of the experiment. Curves represent exponential fits to the data where $P<0.10$. ANCOVAs of these data (using natural-log transformation of the density variable) are shown in Table 4; regression equations using the transformed data are shown in Table 5.

er in the desert source community than the semiarid community for grasses but not for the dicots (Figs. 4 and 5; significant main effects of source community and/or the interaction of source and form in Table 4). In addition, and somewhat surprisingly, in year 1, survival was higher at low irrigation than at high irrigation (Fig. 4; significant main effect of irrigation in Table 4). In year 2, the more intuitive result of increasing survival with increasing irrigation was observed, although only in the coastal community (Fig. 5, significant source community $\times$ irrigation interaction in Table 4). The differences in effects of irrigation between years are likely an artifact due to changes in the watering method-high mortality at high irrigation in year
1 may have been due to excessive force from the hand watering compared to the more gentle irrigation from the sprinkler system installed for the second year.

\section{Size per plant}

As with probability of emergence, effects of density on growth were highly significant overall in both years (Table 4). However, unlike density effects on emergence, the magnitude of the density effects on growth differed considerably between the two years, with much stronger effects in year 2 than in year 1 (Figs. 6 and 7, Table 6), as well as among the other experimental treatments (significant interactions with density in Table 4).

Growth forms did not differ much in the degree of 
TABLE 5. Coefficients for regressions of the probability of survival on cumulative density of emerged seedlings for each combination of year, source community, growth form, and irrigation treatment.

\begin{tabular}{|c|c|c|c|c|c|c|}
\hline Irrigation & Form & $\mathrm{df}$ & Intercept & Slope $\dagger$ & $R$ & $P$ \\
\hline \multicolumn{7}{|c|}{ 1992-1993 Growing season } \\
\hline \multicolumn{7}{|c|}{ Desert community } \\
\hline High & dicot & 17 & 0.048 & 0.082 & 0.455 & 0.050 \\
\hline High & grass & 17 & -0.298 & 0.118 & 0.763 & 0.000 \\
\hline Intermediate & dicot & 8 & 1.174 & -0.053 & 0.376 & 0.284 \\
\hline Intermediate & grass & 8 & 0.045 & 0.085 & 0.704 & 0.023 \\
\hline Low & dicot & 18 & 0.977 & -0.021 & 0.162 & 0.495 \\
\hline Low & grass & 18 & -0.002 & 0.111 & 0.610 & 0.004 \\
\hline \multicolumn{7}{|c|}{ Semiarid community } \\
\hline High & dicot & 18 & 0.132 & 0.096 & 0.674 & 0.001 \\
\hline High & grass & 18 & 0.587 & 0.037 & 0.452 & 0.046 \\
\hline Intermediate & dicot & 18 & 0.425 & 0.064 & 0.592 & 0.006 \\
\hline Intermediate & grass & 18 & 0.637 & 0.037 & 0.427 & 0.061 \\
\hline Low & dicot & 17 & 0.778 & 0.019 & 0.176 & 0.471 \\
\hline Low & grass & 17 & 0.616 & 0.044 & 0.511 & 0.026 \\
\hline \multicolumn{7}{|c|}{ 1993-1994 Growing season } \\
\hline \multicolumn{7}{|c|}{ Desert community } \\
\hline High & dicot & 18 & 0.800 & -0.304 & -0.340 & 0.143 \\
\hline High & grass & 18 & 0.628 & -0.162 & -0.212 & 0.369 \\
\hline Intermediate & dicot & 17 & 0.744 & -0.401 & -0.533 & 0.019 \\
\hline Intermediate & grass & 19 & 0.419 & 0.112 & 0.208 & 0.366 \\
\hline Low & dicot & 18 & 0.609 & -0.535 & -0.390 & 0.089 \\
\hline Low & grass & 18 & 0.539 & -0.174 & -0.121 & 0.611 \\
\hline \multicolumn{7}{|c|}{ Coastal community } \\
\hline High & dicot & 20 & 0.585 & -0.247 & -0.156 & 0.487 \\
\hline High & grass & 20 & 0.606 & 0.726 & 0.516 & 0.014 \\
\hline Intermediate & dicot & 19 & 0.558 & 0.217 & 0.121 & 0.600 \\
\hline Intermediate & grass & 20 & 0.757 & 0.403 & 0.293 & 0.185 \\
\hline Low & dicot & 20 & 0.708 & -1.312 & -0.598 & 0.003 \\
\hline Low & grass & 20 & 0.804 & -0.105 & -0.132 & 0.559 \\
\hline
\end{tabular}

Notes: For the 1992-1993 data, the density measure was natural-log-transformed to linearize the relationships. In 19931994, untransformed data exhibited linear relationships. Untransformed data are shown with negative exponential (19921993) or linear (1993-1994) fits in Figs. 4 and 5, and ANCOVAs comparing slopes on density among treatments are in Table 4. Significant $(P<0.05)$ effects are shown in bold, and nonsignificant trends $(P<0.10)$ are shown in italics.

$\dagger$ Slope values have been multiplied by $10^{4}$.

density dependence in either year (Figs. 6 and 7, Table 4). However, the main effect of growth form was strong: in both years in all source communities, individual dicots were consistently larger than individual grasses (Figs. 6 and 7, Tables 4 and 6; note different scales on figures for grasses and dicots). In 1992-1993, competitive effects on size were stronger in the semiarid source community than in the desert source community, as well as at low vs. high irrigation (Fig. 6, Table 6; significant source and irrigation interactions with density in Table 4). However, in 1993-1994, competition was similarly strong in the desert and coastal source communities (Fig. 7, Tables 4 and 6). Competitive effects on growth still varied significantly with irrigation in this year, with a tendency for stronger effects at low irrigation, but irrigation also was involved in five two- and three-way interactions (Table 4), making it difficult to discern any consistent pattern in the magnitude of competitive effects on size with irrigation (Table 6). In 1992-1993, regardless of competition, plants tended to be larger in the more productive source community and, surprisingly, in the low irrigation treatment (larger intercepts in Fig. 6; Tables
4 and 6). In contrast, in 1993-1994, size was unaffected by either source community or irrigation treatment as main effects (Tables 4 and 6).

\section{Discussion}

The presence of neighbors is an important factor influencing plants at all levels of organization, from the individual to the community. Because plants are sessile, the presence of neighbors is often presumed to have primarily negative consequences on plant performance as a result of neighbors competing to acquire the resources necessary for growth. Such negative effects have been reported in numerous studies (Goldberg and Barton 1992, Gurevitch et al. 1992, Goldberg et al. 1999), although positive effects on performance are also common and receiving more theoretical attention (Bertness and Callaway 1994, Callaway and Walker 1997). In this study, we found that density often had strong impacts on individual performance, but that the magnitude varied considerably, from strongly positive to strongly negative. By understanding the biological and environmental sources of variation in the magnitude and mechanism of density dependence at each life 


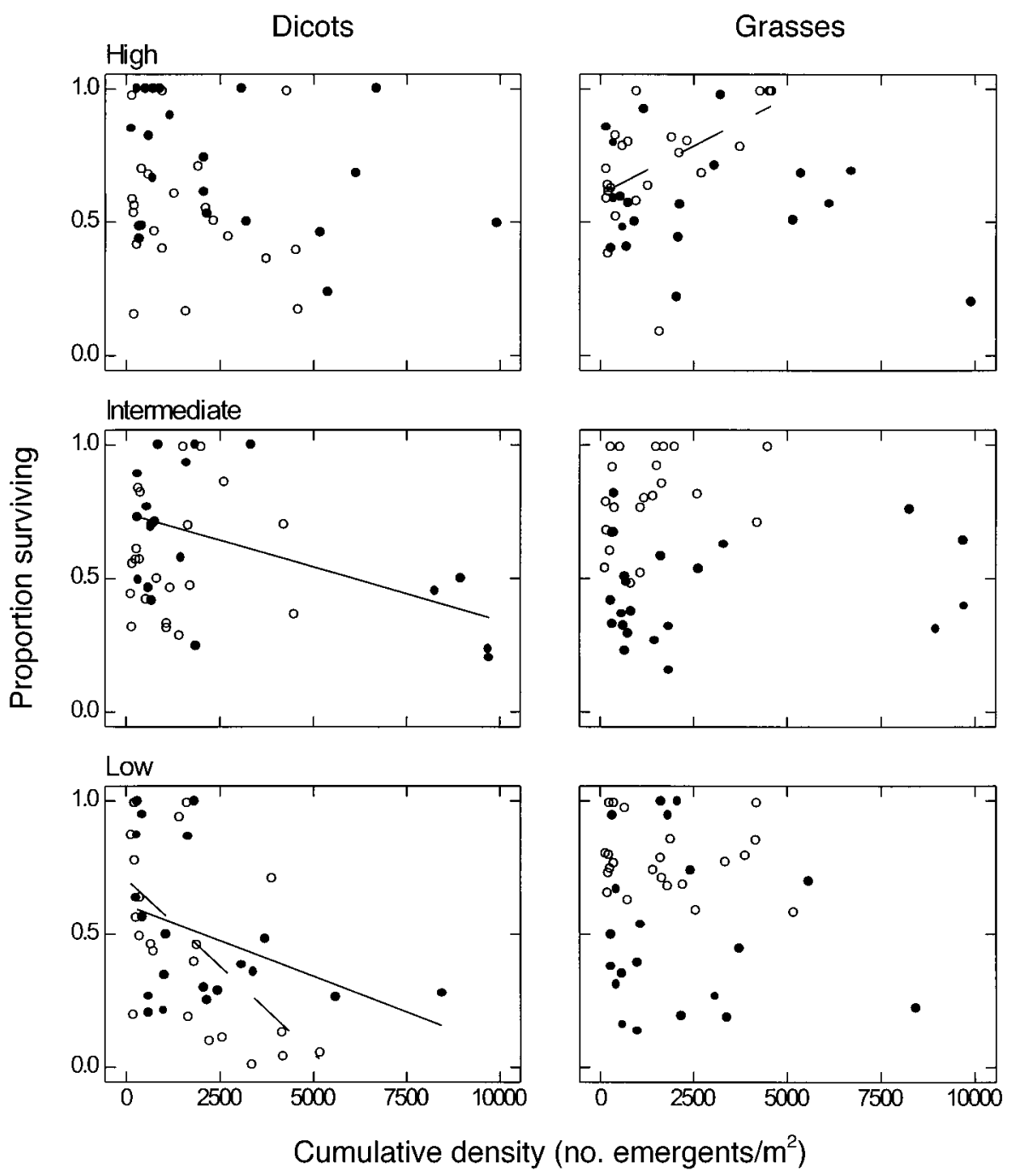

FIG. 5. The effect of density of emerging seedlings on survival to the end of the growing season for dicots and grasses of two source communities (desert, solid lines and filled circles; coastal, dashed lines and open circles) under three irrigation regimes (high, intermediate, and low) in the second year of the experiment. See also Fig. 4 legend.

history stage, we may begin to construct a framework for understanding the demographic processes underpinning community structure (Sinclair 1989). We focus most of the remaining discussion on comparison of life history stages and different demographic parameters, because this has been one of the most neglected areas in both theoretical and empirical studies of interspecific interactions (Sarukhan and Harper 1973, Ehrlen 1995a, $b$, Howard and Goldberg 2001). This neglect means that much of our discussion is necessarily speculative and designed to develop hypotheses, rather than to test existing hypotheses.

Both positive and negative density-dependent effects can be due to a variety of mechanisms besides just modification of resource availability through uptake (Harper 1977); such mechanisms of interaction have been variously called "nonuptake” (Goldberg 1990), "nontrophic" (Bertness and Callaway 1994), or "nonexploitation" interactions. While negative effects are most often assumed to be due to exploitation competition for resources, they could be through nonuptake mechanisms as well, such as allelochemicals (Williamson 1990) or attraction of natural enemies (Connell 1990). Positive effects of neighbors (facilitation) are also common and, by definition, must be mediated through mechanisms other than resource uptake. Many such mechanisms have been demonstrated, including increasing moisture and nutrients, inhibiting herbivores, or providing shelter from harsh environmental conditions in extremely hot or cold climates (reviewed in Callaghan and Emanuelson [1985], Hunter and Aarssen [1988], Goldberg [1990], Callaway [1995], Holm- 


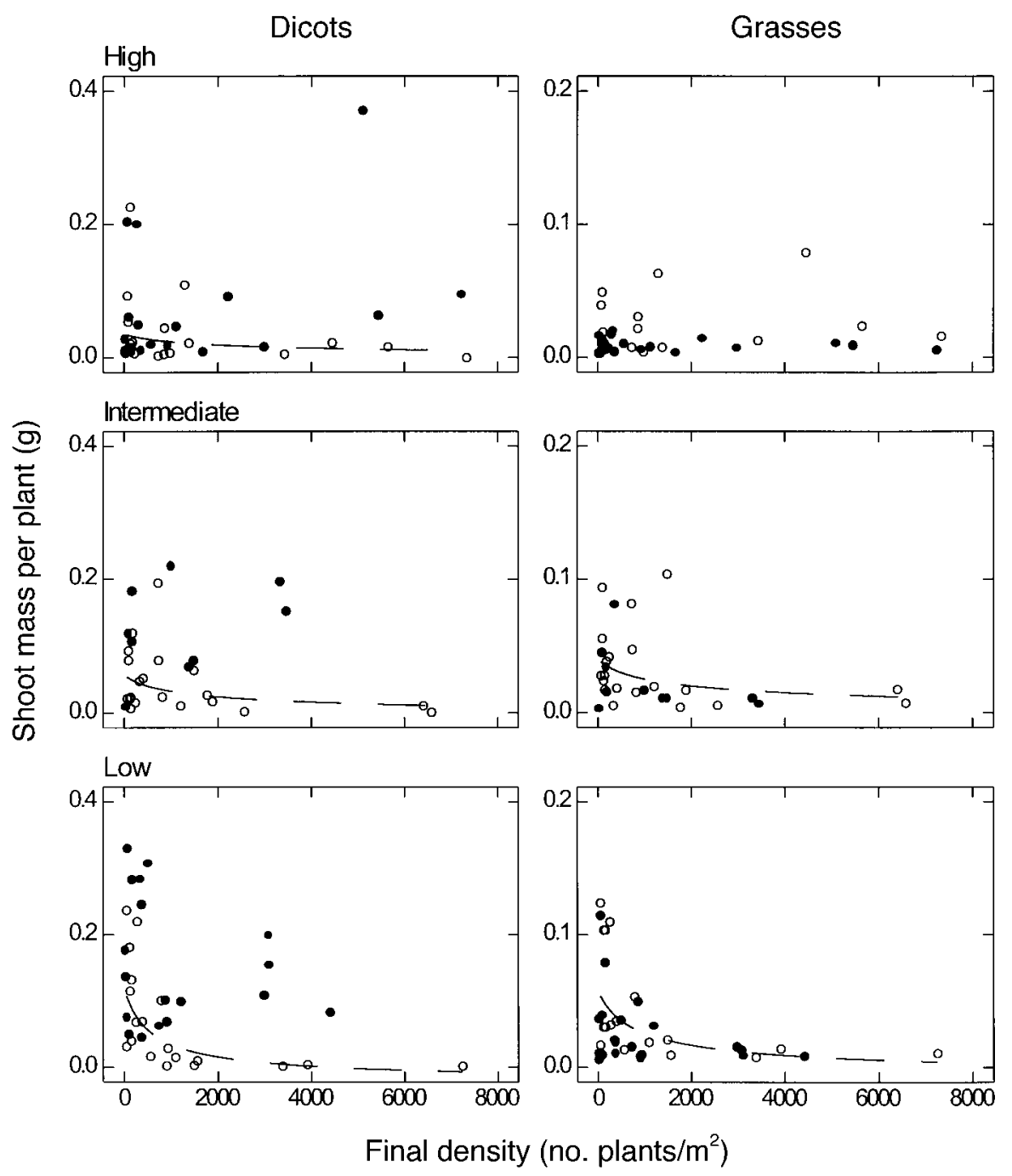

FIG. 6. The effect of density of surviving plants on mean shoot mass per plant at the end of the growing season for dicots and grasses of two source communities (desert, solid lines and filled circles; semiarid, dashed lines and open circles) under three irrigation regimes (high, intermediate, and low) in the first year of the experiment. Curves represent power fits to the data where $P<0.10$. ANCOVAs of these data (using natural $\log -\log$ transformations) are shown in Table 4; regression equations using the transformed data are shown in Table 6.

gren et al. [1997], Holzapfel and Mahall [1999]). Although we did not explicitly investigate the mechanisms underlying the density-dependent effects we quantified in this study, the differences in direction, magnitude, and consistency of occurrence of interactions among life history stages suggest that the mechanisms of interactions differ among stages. Such variation has important implications for the applicability of models of community structure that are based on a single mechanism of interaction and/or do not incorporate age/size structure.

\section{Comparison among life history stages}

Examples of intraspecific density dependence have been reported for many life history stages of plants, including seed dispersal (Baker and O'Dowd 1982), seed predation (Watkinson et al. 1989), germination (Inouye 1980), seedling establishment (Hett 1971), survival and growth during the vegetative phase of the life cycle (Symonides 1983, Condit et al. 1994), flower formation (Bishop and Davey 1984), flowering phenology and outcrossing (Schmitt et al. 1987), and the number of seeds set per plant (Watkinson 1985). Relatively few studies have considered more than one stage in plants (see Howard and Goldberg [2001] for review), although this is common in zoological studies where large differences are found among animal groups in terms of when regulation occurs during the life cycle (Sinclair 1989). We found strong evidence of community-level density dependence at all three life history 

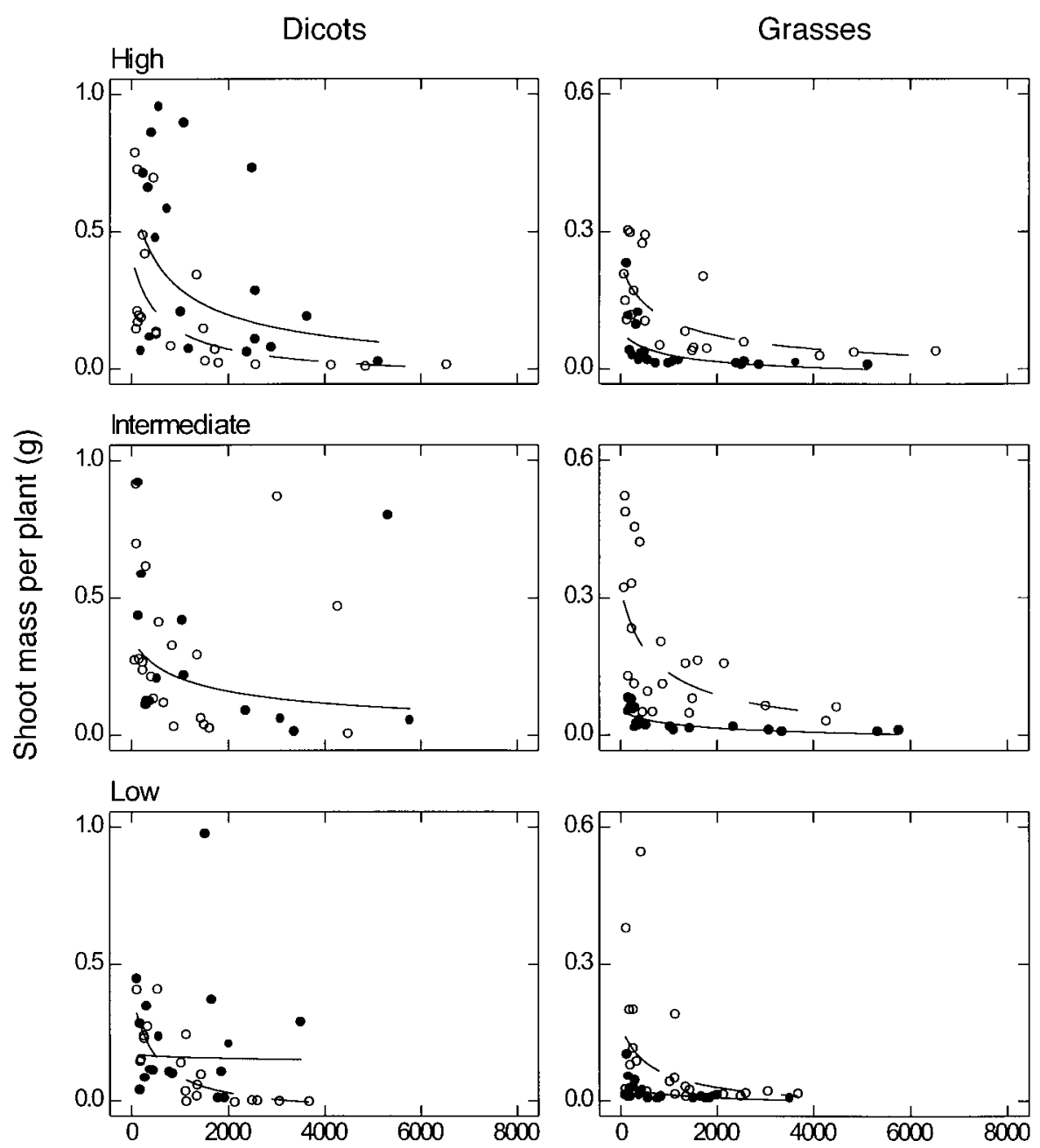

Final density (no. plants $/ \mathrm{m}^{2}$ )

FIG. 7. The effect of density of surviving plants on mean shoot mass per plant at the end of the growing season for dicots and grasses of two source communities (desert, solid lines and filled circles; coastal, dashed lines and open circles) under three irrigation regimes (high, intermediate, and low) in the second year of the experiment. See also Fig. 6 legend.

stages studied in these desert annuals: emergence, survival, and final size (assumed to be correlated with seed production, as is the case for most annual plants; e.g., Miller 1987). However, both the direction and degree of consistency of this density dependence varied considerably among the stages. Thus, studies that focus on only a single stage will miss important patterns that could influence the strength of selection, population dynamics, and community structure.

Emergence.-Perhaps the most surprising result was that the strongest and most consistent competitive effects were experienced at the emergence stage. While inhibition of germination and emergence by existing vegetation is very well known, effects within even-aged stands such as those in this study have rarely been tested. Inouye (1980) demonstrated that the presence of seedlings at high densities inhibits subsequent germination of desert annuals. Dyer et al. (2000) found similar density-dependent inhibition in five of seven species of annual grasses native to the Mediterranean, including genera common in our source communities. In even-aged stands starting from seeds, the seeds or just-emerged seedlings are highly unlikely to be competing with each other for access to water, nutrient, or light resources. Thus, the mechanism is most likely a form of interference competition, rather than exploitation competition. Other studies have reported effects on germination of high seed densities (negative, Palmblad 1968, Murray 1998; positive, Linhart 1976) while some have reported no effect (McMurray et al. 1997, Murray 1998); these studies have largely been conducted un- 
TABLE 6. Coefficients for log-log regressions of mean mass per plant on final density of surviving plants, for each combination of year, source community, growth form, and irrigation treatment.

\begin{tabular}{|c|c|c|c|c|c|c|}
\hline Irrigation & Form & $\mathrm{df}$ & Intercept & Slope & $R$ & $P$ \\
\hline \multicolumn{7}{|c|}{ 1992-1993 Growing season } \\
\hline \multicolumn{7}{|c|}{ Desert community } \\
\hline High & dicot & 16 & -4.723 & 0.221 & 0.311 & 0.209 \\
\hline High & grass & 17 & -5.238 & 0.050 & 0.137 & 0.577 \\
\hline Intermediate & dicot & 8 & -4.156 & 0.322 & 0.431 & 0.214 \\
\hline Intermediate & grass & 8 & -3.597 & -0.092 & -0.148 & 0.683 \\
\hline Low & dicot & 18 & -0.505 & -0.224 & -0.375 & 0.103 \\
\hline Low & grass & 18 & -3.374 & -0.107 & -0.202 & 0.392 \\
\hline \multicolumn{7}{|c|}{ Semiarid community } \\
\hline High & dicot & 18 & -2.135 & -0.295 & -0.394 & 0.085 \\
\hline High & grass & 18 & -3.937 & 0.002 & 0.002 & 0.992 \\
\hline Intermediate & dicot & 18 & -1.429 & -0.339 & -0.446 & 0.049 \\
\hline Intermediate & grass & 18 & -2.060 & -0.263 & -0.432 & 0.057 \\
\hline Low & dicot & 17 & -1.497 & -0.799 & -0.806 & 0.000 \\
\hline Low & grass & 17 & -1.018 & -0.418 & -0.677 & 0.001 \\
\hline \multicolumn{7}{|c|}{ 1993-1994 Growing season } \\
\hline \multicolumn{7}{|c|}{ Desert community } \\
\hline High & dicot & 19 & 3.353 & -0.676 & -0.594 & 0.005 \\
\hline High & grass & 19 & 1.101 & -0.716 & -0.824 & 0.000 \\
\hline Intermediate & dicot & 18 & 2.646 & -0.568 & -0.436 & 0.054 \\
\hline Intermediate & grass & 19 & 0.083 & -0.592 & -0.874 & 0.000 \\
\hline Low & dicot & 18 & 2.649 & -0.665 & -0.465 & 0.039 \\
\hline Low & grass & 18 & -1.363 & -0.465 & -0.601 & 0.005 \\
\hline \multicolumn{7}{|c|}{ Coastal community } \\
\hline High & dicot & 20 & 2.378 & -0.699 & -0.802 & 0.000 \\
\hline High & grass & 20 & 1.468 & -0.551 & -0.746 & 0.000 \\
\hline Intermediate & dicot & 20 & 0.322 & -0.291 & -0.285 & 0.198 \\
\hline Intermediate & grass & 20 & 0.991 & -0.457 & -0.704 & 0.000 \\
\hline Low & dicot & 20 & 7.880 & -1.587 & -0.825 & 0.000 \\
\hline Low & grass & 20 & 0.758 & -0.569 & -0.604 & 0.003 \\
\hline
\end{tabular}

Notes: Untransformed data are shown with power fits in Figs. 6 and 7, and ANCOVAs comparing slopes on density among treatments are in Table 5. Significant $(P<0.05)$ effects are shown in bold and nonsignificant trends $(P<0.10)$ are shown in italics.

der highly controlled laboratory conditions, using intraspecific density variation only.

The density-dependent emergence we observed could be due to either of two general classes of processes: effects of seeds themselves on germination of other seeds, or effects of already germinated seedlings on subsequent germination of seeds. Other experiments and analyses in this system by R. Turkington et al. (unpublished data) and Peltzer et al. (unpublished data) suggest that effects of seeds themselves are more likely. Possible mechanisms include increased local levels of $\mathrm{CO}_{2}$ with increasing seed density, or allelochemicals washed from seed coats or roots or from fine organic matter that remained with the seed bank after sieving. Inhibition by $\mathrm{CO}_{2}$ from respiration of germinating seeds is unlikely, because concentrations are unlikely to be high enough in shallow soil, especially in sand (cf. Baskin and Baskin 1998). We also doubt that the nonseed organic matter has a significant effect, because the coastal community in particular has much more organic matter associated with the seed bank than do the other two communities, yet does not show any greater density-dependent inhibition of emergence. A priori, allelopathic effects seem unlikely, because these are usually thought to be highly specific, but we observed germination inhibition in most species in each source community (D. E. Goldberg et al., unpublished data), and the magnitude is highly consistent between source communities and years. On the other hand, germination inhibition from surficial chemicals on seed hulls is known from two grass genera that occur in our communities: Avena (Naylor and Christie 1956) and Aegilops (Wurzburger and Leshem 1969; Dyer et al. 2000), providing some support for this mechanism, at least intraspecifically (Evenari 1949). Ongoing experiments are investigating the phenomenon.

Survival.-For survival, the positive or nonsignificant effects of density indicate that exploitation competition is also unimportant at this stage. Callaway (1995) and Holmgren et al. (1997) have argued that a common mechanism by which nurse plants facilitate seedlings or smaller herbaceous plants in deserts is through reduction of temperatures and evapotranspiration in dense stands, and that this kind of facilitation should increase as water becomes more limiting.

While the term "nurse plant" seems inappropriate to the even-aged stands of annuals we studied, it nevertheless is possible that similar processes could occur 
whenever individuals differ in size (e.g., due to differences we observed in emergence time in these experiments; R. Turkington et al., unpublished data). However, our results were not consistent with the expectation that facilitation is stronger at lower productivity. In fact, if anything, the reverse occurred, with more intense competitive interactions at low irrigation. An alternative mechanism, more specific to the particular experimental system we studied, could be that higher densities reduced wind speed, which reduced the potential for burial, root exposure, or abrasion by blowing sand. Although not quantified, blowing sand appeared to be an occasional source of mortality in the experimental garden. However, it is unclear why this mechanism should have operated more strongly in the first year of the experiment or at higher irrigation and, in any case, such mortality would be less likely to occur in the field, because the source sites had a greater amount of stabilized sand than in the recently constructed garden. Yet another possible mechanism could operate if the plants under high irrigation exhibited the common response of decreasing allocation to roots in response to irrigation, especially early in the growing season. This morphology could then have left the plants at high irrigation more susceptible to competition for belowground resources at high density (R. Callaway, personal communication). Although we cannot test this hypothesis with the available data, it is consistent with our observations of root allocation in response to water for isolated individuals of many of the species in these communities (Dyer et al. 2001). Thus, while we cannot establish the mechanism(s) of density-dependent survival in this experiment, our data do suggest that the interaction is neither traditional exploitation competition nor a version of the standard nurse effect, now well documented for many desert plants (reviewed in Callaway [1995], Holmgren et al. [1997]).

Growth.-Increasing density had overall negative effects on growth in both years, but effects varied considerably, especially between irrigation treatments and years. These are the two experimental factors most likely to have affected water and/or nutrient availability, and therefore this result is consistent with the idea that exploitation competition is the primary mechanism of interactions influencing growth (see Discussion: Comparisons among irrigation treatments and Discussion: Comparisons among years for further comments). Light was unlikely to be a limiting resource, because even in the most productive plots, the minimum photosynthetically active radiation (PAR) observed at ground level at the end of the growing season was $\sim 20 \%$ of full sunlight, and most plots even at high irrigation and high density had much higher values.

Growth vs. survival.-The differences in direction and magnitude of density dependence between survival and growth are consistent with a growing body of experimental evidence that effects of neighbors on growth are usually negative, while effects on survival are either less negative or more likely to be positive or nonsignificant (reviews in Goldberg and Novoplansky 1997, Goldberg et al. 1999). This evidence ranges from wetlands (Callaway and King 1996) to old fields (De Steven 1991 $a, b$, Howard and Goldberg 2001) to deserts, as considered here (see also Kadmon [1995]). The causes of differences in density dependence of survival vs. growth have not been addressed explicitly in any study of which we are aware, but their frequent occurrence suggests that a general explanation based on fundamental differences between processes affecting survival and growth is required. The simplest explanation is that survival is an all/none phenomenon, while growth is continuous and thus can register smaller effects. While such an explanation likely at least partially accounts for the observation of less negative or nonsignificant effects of neighbors on survival than on growth, it cannot account for the more frequent positive effects on survival. We suggest that a broader explanation could be based on explicitly distinguishing between the roles of resource retention and resource acquisition in determining plant success (Chapin 1980).

Survival merely requires sufficient resources to maintain essential processes, which may be satisfied either by taking up new resources to balance any losses, or by restricting loss of existing resources. In contrast, growth requires the acquisition of additional new resources beyond the mere maintenance level; retention is not sufficient. Therefore, any differences in effects of neighbors on survival vs. growth may be accounted for by differences in effects of neighbors on the processes of resource retention vs. resource uptake. As long as resources are limiting, the uptake by neighbors will reduce availability and, therefore, uptake of resources by other plants. This may or may not affect survival (depending on the importance of uptake vs. retention of resources), but should definitely affect growth, which requires new resource acquisition. Thus, if exploitation competition is the only mechanism of interaction, negative effects on growth should be more common and larger than negative effects on survival, consistent with the general pattern observed. However, in addition to this negative interaction, neighbors may have positive effects on resource retention, although only one mechanism is widely documented to our knowledge: shading by neighbors reduces temperatures, which can reduce water loss by transpiration. To the extent that survival is affected by the ability to reduce resource loss, as well as through the ability to take up resources, this could lead to positive effects of neighbors on survival. This mechanism of interaction suggests the greater potential for less negative or even positive effects of neighbors on survival, but generally negative effects on growth.

This explanation will not apply to all situations, however, because neighbors can also have positive effects on resource availability and, therefore, on uptake (reviews in Goldberg [1990], Callaway [1995], Caldwell 
et al. [1998]). These effects could either more than counteract any simultaneously occurring effects of exploitation competition (resulting in net positive effects on resource uptake), or could mitigate the expected effects of exploitation competition, resulting in smaller negative effects of neighbors on uptake and, thereby, growth. Thus, even if only uptake and not retention of resources is critical, positive effects of neighbors are possible.

Little data exist to evaluate the hypothesis that resource retention is more important for survival than for growth, given that most data on plant-plant interactions simply quantify effects of neighbors on plant performance, rather than on the mechanisms determining those net effects. However, it does suggest that more effort should be devoted to understanding the mechanisms of interactions as a basis for developing models that incorporate demographic patterns that are more realistic. As the evidence for differences between survival and growth responses to competition becomes stronger, understanding of the mechanisms that cause this difference, as well its consequences, becomes more important.

Consistency of density dependence among environments and growth forms.-The hypothesized differences in mechanisms of density dependence among the three stages are consistent with the observation that the magnitude of density dependence is more consistent among abiotic environments for emergence than for survival and growth. If effects on emergence are not related to resource levels, but to, say, allelochemicals, then it would be predicted that these effects should be independent of environmental variation in resource levels (between years and irrigation treatments), but not be independent of taxonomic identity (growth form or source community). In contrast, if density effects on survival and on growth are due to effects of plants on resource requirements or availability (either positively or negatively), we would predict that their effects would vary among environments that vary in resource availability, as well as among species or species groups. Our results are consistent with these predictions, with more two- and three-way interactions involving density and irrigation, especially for growth.

Consequences of variation among life stages.-The variation in mechanism and magnitude of interactions among life history stages has important implications for the applicability of most current models of competition in plants. Models currently in use are either completely phenomenological and unstructured (no age/size dependence; e.g., Watkinson 1980, Law and Watkinson 1987; classic Lotka-Volterra models), or rely almost exclusively on processes of exploitation competition and model survival solely as a simple monotonic function of growth, without explicitly including density-dependent emergence at all (e.g., Tilman 1988, Smith and Huston 1989, Pacala et al. 1996). Both of these kinds of models have been highly im- portant in developing a rigorous basis for our understanding of the process of competition. Nevertheless, the existence of qualitatively different responses of different stages that are likely due to different mechanisms suggests that a different approach to model construction is also needed. Specifically, while our observation of negatively density-dependent emergence may not be general to other systems, or perhaps only to other desert annual systems, the differences we observed between survival and growth responses to competition appear to be quite general. Therefore, as well as developing general models of nonuptake mechanisms of interaction, it will be especially important to develop models that explicitly incorporate distinct mechanistic functions for density-dependent survival as well as for growth, and to initiate studies that examine these mechanisms.

\section{Comparison among growth forms}

During emergence and survival, grasses were consistently better competitors (sensu lato) than dicots, i.e., grasses experienced less inhibition of germination at high seed density, and their survival was more likely to be facilitated at high density. Grasses were also superior to dicots in overall emergence and survival, regardless of density. These are both stages in which the mechanism of interaction is unlikely to be resource competition, and the traits of grasses that make them generally superior at these stages in this system is not clear. For the more commonly studied stage of growth and size, the two growth forms did not differ in competitive ability, although individual dicots were on average much bigger than individual grasses.

That the emergence index for monocots is higher on average than for dicots could simply mean that there are more grass seeds than dicot seeds in the seed bank, or it could mean that grass seeds have a high probability of germination. However, the presence of more grass seeds in the initial seed bank could itself be an indicator of past long-term competitive success. These patterns in competitive ability and overall performance are consistent with the patterns of abundance of the two growth forms in the experimental plots and all the natural communities, where grasses were the dominants in terms of both numbers of individuals and, in most cases, biomass (D. E. Goldberg et al., unpublished data). Along with this generally greater abundance, grasses were also the superior community-level competitors, in the sense that grasses typically increased in relative biomass and relative density as initial community density increased in both years and both communities (D. E. Goldberg et al., unpublished data). Together, these results suggest the hypothesis that the nontrophic mechanisms of interaction that apparently operate on emergence and survival determine the structure of both these communities, further emphasizing the importance of developing models of community structure that do not 
rely exclusively on exploitation competition as the main mechanism of interaction.

\section{Comparison among source communities}

Grime $(1977,1979)$ has predicted that species from more productive communities should generally be stronger competitors. In our context, this could predict that competition should be stronger in the semiarid (year 1) or coastal (year 2) communities than in the desert community, within any given irrigation level. However, the prediction does not apply to the average effects quantified in this study, because, while this hypothesis predicts that such species should have stronger abilities to suppress plants (competitive effect), it does not address the possibility that they should also have stronger abilities to resist suppression (competitive response). Therefore, the average interactions may not be any different; the greater tolerance of suppression could balance the greater ability to suppress. Consistent with the importance of both effect and response competitive abilities, the source communities tended to have similar competition intensities overall, with only one of six possible interactions between density and source being significant.

Although we did not expect (and did not find) any differences between source communities in competitive ability, we did expect differences in their absolute performance and in how their performance depended on water availability, irrespective of the density of potentially competing plants. Specifically, it has often been predicted that plants from more productive environments should have higher intrinsic growth rates overall and greater responsiveness in growth to increases in resources (Grime 1977, Chapin 1980, Lambers and Poorter 1992). Most of our results were not consistent with this prediction. While plants from the semiarid source community were larger overall than those in the desert community in the first year, in the second year, mean size did not differ between the coastal and desert source communities. Furthermore, the communities have similar growth responsiveness to irrigation in both years (few source community $\times$ irrigation interactions). The lack of differences in growth or growth responsiveness to irrigation between source communities is unlikely to be due to simple lack of power or high variation in the data. While these results are from a mixture of species in an experimental garden, they are qualitatively identical to results using a subset of the same species grown as isolated seedlings in a growth chamber (Dyer et al. 2001). The most likely explanation for the absence of greater growth and growth plasticity in the more productive communities is that these annual plants effectively all experience a relatively productive environment in the field, in the sense that they germinate and grow only during temporarily productive periods in otherwise harsh environments. While the length and frequency of these rainfall pulses differ along the rainfall gradient, growth is still restricted to those pulses in all three source habitats we studied.

\section{Comparison among years}

Results differed considerably between the two years: emergence, survival, and plant size all tended to be higher in the second year, regardless of density. This may, at least in part, be an artifact of differences in experimental protocols. For example, the larger final size in year 2 could be due to the earlier planting (by $\sim 6 \mathrm{wk}$ ) and longer growing season. On the other hand, the difference in emergence was probably even greater than these results indicate, because the weekly censuses in a subset of plots suggested that emergence was probably underestimated in 1994 because of mortality before the emergence census. Alternatively, the difference in results could be due to differences in species composition between years.

In addition, the effects of increasing density tended to be more negative in the second year, especially for survival and growth. This is less likely to be an artifact of experimental protocols, but is still difficult to interpret. While total precipitation over the growing season was similar between the two years $(\sim 55-60 \%$ of the long-term precipitation average at Sde Boqer), spacing of rainfall events and temperature at the relative to periods of high water availability differed considerably. One possible cause of differences between years is changes in species composition: even with the desert source community, species composition changed considerably between years. Much longer time series will be necessary to understand the sources of year-toyear variation in density dependence.

\section{Comparison among irrigation treatments}

While the irrigation treatments did result in significant differences in productivity, they were not as large as we expected, perhaps because of greater nutrient limitation in the garden than in the field, resulting in less response to water. Samples taken in 1997 from the source sites and from the garden plots during other experiments show that phosphorus availability was much lower in the garden than the field for the desert source community, while nitrogen was similar (D. E. Goldberg et al., unpublished data). In the coastal community, nitrogen availability was lower in the garden than in the field, while phosphorus was similar (D. E. Goldberg et al., unpublished data). While the reasons for the difference between sources are unclear, at least one nutrient was significantly lower in the garden than under field conditions for both source communities. Although these nutrient measurements were taken several years subsequent to the demographic data presented in this study, they do suggest that nutrients were less available in the garden than in the field, thereby potentially reducing the response to added water.

Nevertheless, the treatments did differ in productivity, enabling tests of the conflicting predictions about 
the intensity of competition along a productivity gradient. Grime $(1973,1977)$ predicts that the intensity of competition will be highest in more productive environments. However, Newman (1973) and Tilman (1988) predict that the intensity of competition will remain relatively constant along a productivity gradient, but competition will primarily be for soil resources in low productivity areas, and for light in higher productivity areas. Goldberg and Novoplansky (1997) reconciled these conflicting predictions by arguing that the Grime prediction held for survival response to competition, while the Newman-Tilman prediction held for growth response to competition. In separate models, Bertness and Callaway (1994) and Holmgren et al. (1997) have argued that facilitation is more likely under stressful conditions (see Discussion: Growth vs. survival). Because the net effect of interactions is always due to a combination of simultaneously occurring mechanisms that can be both positive and negative, greater facilitation under stressful and unproductive conditions can lead to either more interactions that are net positive, or simply less intense negative interactions, i.e., the Bertness-Callaway hypothesis could lead to a result similar to that predicted by Grime, although for different reasons.

While the statistical results showed that competition intensity depended on irrigation for growth and, in one year, for survival, the actual patterns were somewhat variable among source communities, growth forms, and years. However, the most common pattern was that competition was more intense at low irrigation than at high irrigation, i.e., inconsistent with all the predictions we have described. A similar result was found in a meta-analysis of data from 14 published experiments on competition intensity, using standing crop as an estimate of productivity (Goldberg et al. 1999). They found, as we did in this study, that competition intensity tended to be either constant or weaker as productivity increased, but certainly did not become stronger with productivity as predicted by Grime $(1973,1977)$. While the meta-analysis was restricted to herbaceous plants, most were perennials in relatively temperate ecosystems, in contrast to the desert annuals of our study system. The similarity in result despite differences in design, types of communities, and types of species further supports the generality of the finding.

At least two possibilities exist to explain these results. (1) A greater number of natural enemies may be supported by or attracted to high productivity sites, and their consumption may reduce densities enough to lower competition intensity, relative to the amount of resources supplied (Cebrian and Duarte 1994). However, we observed very little herbivory in the experimental communities, and this hypothesis seems unlikely to apply, at least to the desert annual community we studied. (2) Because root and shoot competition vary in opposite directions along productivity gradients (Wilson and Tilman 1991, 1995), if root competition is consis- tently greater than shoot competition, it could result in the total competitive effects declining with productivity. This may well apply to the experimental communities we studied, because light levels were consistently relatively high and unlikely to be limiting, even at the highest irrigation and density treatments. If light competition did not occur at all, the high irrigation treatments may have alleviated competition for water and/ or nutrients (nutrients are likely to increase with increasing water because of increased microbial breakdown of the organic matter accompanying the seed bank). A similar explanation may apply to some of the studies reviewed by Goldberg et al. (1999); however, few studies report light levels, and none also report on light requirements of the study species.

\section{Some caveats}

Using entire growth forms within diverse communities to characterize demographic responses to various environmental conditions has the following major advantages: the results are broadly representative of particular communities, and the responses measured are in a realistic context of multispecies assemblages that incorporate all potential interactors. However, a potential disadvantage is that strong differences in demography among species could dictate the results so that changes in species composition between environments could confound direct effects of environment on demographic responses. While we cannot completely eliminate this possibility, other analyses show that the irrigation treatments had no significant effect on species composition, either in terms of relative density or relative biomass (D. E. Goldberg et al., unpublished data). More generally, our major focus in this paper is to compare responses to density among life history stages, and these comparisons were qualitatively consistent, regardless of irrigation.

A similar caveat and response applies to extrapolation of these results from an experimental garden to field conditions. Despite the differences in environmental conditions between the garden and the field, the total density of plants and the relative density of different species were very similar between each of the natural source sites and the equivalent experimental plots (treatments with natural density and irrigation regime for each source) (D. E. Goldberg et al., unpublished data). However, there were some discrepancies in growth rates and, therefore, in both total biomass and relative biomass contribution of different species, perhaps because of differences in temperature between the desert garden site and the more mesic of the source sites. Thus, while results in the garden cannot be quantitatively extrapolated to the field, our major conclusions should be directly applicable.

\section{Conclusions and directions for future research}

Our results suggest two major conclusions, which superficially may seem contradictory. On one hand, our 
results clearly indicate that models of species interactions must include more than simply exploitation competition as a predominant mode of interaction among plants and thus point to a need for greater complexity in developing theory. Are there important consequences for population and community dynamics of having different mechanisms of interaction be important at different demographic stages and in different environments? For example, we speculate that the existence of different mechanisms of interaction will often lead to shifts in competitive hierarchies between life history stages because of differences in traits that convey competitive superiority. Such shifts should reduce the rate of competitive exclusion, and, in conjunction with other mechanisms such as disturbance or variable environments, could maintain higher diversity.

On the other hand, our results, combined with recent reviews and accumulating literature, suggest several emerging consistencies in the net effect of all types of interactions that could lead to greater generalizability among systems and thus simplify developing theory. Further empirical research should focus on comparisons among life history stages and demographic parameters for various types of perennial plants, in order to test the hypotheses that exploitation competition consistently has its major impacts on growth, while facilitation has its major effects on survival. If so, survival is typically governed by mechanisms of interaction quite different from those governing growth and must be modeled differently. More studies also need to include emergence as a critical demographic stage and compare impacts with other demographic parameters and ages. In addition, we need to compare mechanisms and effects of life history stages among types of physical environments. While comparisons of competitive/facilitative intensity along productivity gradients are now very frequent in the plant literature, they almost entirely focus on growth responses to neighbors, which may not always (or even often?) be the critical stage for population dynamics. Finally, the variation in mechanism and magnitude among stages demands a return to studies of population regulation and questions about the stages most important for regulation and limitation (Watkinson 1985). How does this vary among types of plants and types of environments? Silvertown and colleagues (Silvertown et al. 1993, 1996, Franco and Silvertown 1996) have made a start on using existing studies of population dynamics to assess the importance of different stages, but without taking into explicit account different kinds of density dependence at each stage. Empirical work on this problem is probably the most critical gap in our understanding for further development of comprehensive theory of community structure in plants.

\section{ACKNOWLEDGMENTS}

We are grateful to the many people who sliced, scalpeled, stapled, stitched, and silicon-sealed boxes; scraped, screeded, shoveled, scooped, sieved, sifted, and smoothed sand; sampled and sowed seed, surveyed seedlings, and who harvested, identified, and weighed plants: Achmed Al'Azma, Iris Schmidt, Anat DuMosch, Sergei Volis, the television producers (Leonid and Mikhail), Amit Harpaz, Max Taub, Hagit Volin, Larissa Losovsky, Yoram Ayal, Jessica Gurevitch, and members of the Turkington family. We especially appreciate the help of Avinoam Danin, who showed us possible field sites and verified plant identifications. Tim Howard, Wes Hochaska, and Burt Kotler helped with data analyses, and Dunrie Greiling, Tara Rajaniemi, and Katie Nash Suding waded through the entire draft manuscript to make helpful comments. Ray Callaway and two anonymous reviewers provided exceptionally helpful and thorough reviews. We are also indebted to Benjamin Goldberg and Inbar DuMosch who patiently waited to be born until just after the first field season. Financial support was provided by the U.S.-Israel BiNational Science Foundation (BSF 91-00179 to D. Goldberg and L. Olsvig-Whittaker), the National Science Foundation (DEB 96-2973 to D. Goldberg, R. Turkington, and Jessica Gurevitch), a Natural Science and Engineering Research Council of Canada Operating Grant, and a Killam Fellowship (to R. Turkington) and a grant from the Office of the Vice President for Research at the University of Michigan (to D. Goldberg). This is publication no. 306 of the Mitrani Department of Desert Ecology, Blaustein Institute of Desert Resesarch, Ben Gurion University, Israel.

\section{Literature Cited}

Allen, E. B., and R. T. T. Forman. 1976. Plant species removals and old-field community structure and stability. Ecology 57:1233-1243.

Baker, G. A., and D. J. O'Dowd. 1982. Effects of parent plant density on the production of achene type in the annual Hypochoeris glabra. Journal of Ecology 70:201-215.

Barkham, J. P. 1980. Population dynamics of the wild daffodil (Narcissus pseudonarcissus). II. Changes in number of shoots and flowers, and the effect of bulb depth on growth and reproduction. Journal of Ecology 68:635-664.

Baskin, C. C., and J. M. Baskin. 1998. Seeds: ecology, biogeography, and evolution of dormancy and germination. Academic Press, San Diego, California, USA.

Bertness, M. D., and R. M. Callaway. 1994. Positive interactions in communities. Trends in Ecology and Evolution 9:191-193.

Bishop, G. F., and A. J. Davy. 1984. Significance of rabbits for population regulation of Hieraceum pilosella in Breckland. Journal of Ecology 72:273-284.

Caldwell, M. M., T. E. Dawson, and J. H. Richards. 1998. Hydraulic lift: consequences of water efflux from the roots of plants. Oecologia 113:151-161.

Callaghan, T. V., and U. Emanuelsson. 1985. Population structure and processes of tundra plants and vegetation. Pages 399-439 in J. White, editor. The population structure of vegetation. Junk, Dordrecht, The Netherlands.

Callaway, R. M. 1995. Positive interactions among plants. Botanical Review 61:306-349.

Callaway, R. M., and L. King. 1996. Temperature-driven variation in substrate oxygenation and the balance of competition and facilitation. Ecology 77:1189-1195.

Callaway, R. M., and L. R. Walker. 1997. Competition and facilitation: a synthetic approach to interactions in plant communities. Ecology 78:1958-1965.

Caswell, H. 1989. Matrix population models. Sinauer, Sunderland, Massachusetts, USA.

Cebrian, J., and C. M. Duarte. 1994. The dependence of herbivory on growth rate in natural plant communities. Functional Ecology 8:518-525.

Chapin, F. S., III. 1980. The mineral nutrition of wild plants. Annual Review of Ecology and Systematics 11:233-260.

Condit, R., S. P. Hubbell, and R. B. Foster. 1994. Density 
dependence in two understory tree species in a neotropical forest. Ecology 75:671-680.

Connell, J. H. 1990. Apparent versus "real" competition in plant communities. Pages 9-26 in J. B. Grace and D. Tilman, editors. Perspectives on plant competition. Academic Press, San Diego, California, USA.

Courchamp, F., T. Clutton-Brock, and B. Grenfell. 1999. Inverse density-dependence and the Allee effect. Trends in Ecology and Evolution 14:405-410.

Crawley, M. J. 1990. The population dynamics of plants. Philosophical Transactions of the Royal Society B 330(1257): 125-140.

Crawley, M. J. 1997. The structure of plant communities. Pages 475-531 in M. J. Crawley, editor. Plant ecology. Second edition. Blackwell Scientific, Oxford, UK.

De Steven, D. 1991a. Experiments on mechanisms of tree establishment in old-field succession: seedling emergence. Ecology 72:1066-1075.

De Steven, D. 1991b. Experiments on mechanisms of tree establishment in old-field succession: seedling survival and growth. Ecology 72:1076-1088.

Dyer, A. R., A. Fenech, and K. J. Rice. 2000. Accelerated seedling emergence in inter-specific competitive neighborhoods. Ecology Letters 3:523-529.

Dyer, A. R., R. Turkington, D. E. Goldberg, and C. Sayre. 2001. Effects of growing conditions and source habitat on plant traits and functional group definition. Functional Ecology 15:85-95.

Ehrlen, J. 1995a. Demography of the perennial herb Lathyrus vernus. 1. Herbivory and individual performance. Journal of Ecology 83:287-295.

Ehrlen, J. 1995b. Demography of the perennial herb Lathyrus vernus. 2. Herbivory and population dynamics. Journal of Ecology 83:297-308

Evenari, M. 1949. Germination inhibitors. Botanical Review 15:153-194.

Feinbrun-Dothan, N., and A. Danin. 1991. Analytical flora of the Land of Israel. Cana, Jerusalem, Israel.

Ford, H. 1981. The demography of three populations of dandelion. Biological Journal of the Linnaean Society 15:111.

Fowler, N. L. 1981. Competition and coexistence in a North Carolina grassland. II. The effects of the experimental removal of species. Journal of Ecology 69:843-854.

Fowler, N. L. 1995. Density-dependent demography in two grasses: a five-year study. Ecology 76:2145-2164.

Franco, M., and J. Silvertown. 1996. Life history variation in plants: an exploration of the fast-slow continuum hypothesis. Philosophical Transactions of the Royal Society of London 351:1341-1348.

Goldberg, D. E. 1990. Components of resource competition in plant communities. Pages 27-49 in J. Grace and D. Tilman, editors. Perspectives in plant competition. Academic Press, San Diego, California, USA.

Goldberg, D. E., and A. M. Barton. 1992. Patterns and consequences of interspecific competition in natural communities: field experiments with plants. American Naturalist 139:771-801.

Goldberg, D. E., and G. Estabrook. 1998. A method for comparing diversity and species abundances among samples of different sizes and an experimental example with desert annuals. Journal of Ecology 86:983-988.

Goldberg, D. E., and K. Landa. 1991. Competitive effect and response: hierarchies and correlated traits in the early stages of competition. Journal of Ecology 79:1013-1030.

Goldberg, D. E., and A. Novoplansky. 1997. On the relative importance of competition in unproductive environments. Journal of Ecology 85:409-418.

Goldberg, D. E., T. Rajaniemi, J. Gurevitch, and A. StewartOaten. 1999. Empirical approaches to quantifying inter- action intensity: competition and facilitation along productivity gradients. Ecology 80:1118-1131.

Goldberg, D. E., R. Turkington, and L. Olsvig-Whittaker. 1995. Quantifying the community-level effects of competition. Folia Geobotanica and Phytotaxonomica 30:231242

Grace, S. L., and W. J. Platt. 1995. Effects of adult tree density and fire on the demography of pregrass stage juvenile longleaf pine (Pinus palustris Mill.). Journal of Ecology 83:75-86.

Grime, J. P. 1973. Competitive exclusion in herbaceous vegetation. Nature 242:344-347.

Grime, J. P. 1977. Evidence for the existence of three primary strategies in plants and its relevance to ecological and evolutionary theory. American Naturalist 111:1169-1194.

Grime, J. P. 1979. Plant strategies and vegetation processes. John Wiley \& Sons, Chichester, UK.

Gurevitch, J., L. L. Morrow, A. Wallace, and J. S. Walsh. 1992. A meta-analysis of competition in field experiments. American Naturalist 140:539-572.

Harper, J. L. 1967. A Darwinian approach to plant ecology. Journal of Ecology 55:247-270.

Harper, J. L. 1977. The population biology of plants. Academic Press, London, UK.

Harper, J. L., and J. White. 1974. The demography of plants. Annual Review of Ecology and Systematics 5:419-463.

Harrison, S., and N. Cappuccino. 1995. Using density-manipulation experiments to study population regulation. Pages 131-148 in N. Cappuccino and P. W. Price, editors. Population dynamics: new approaches and syntheses. Academic Press, Orlando, Florida, USA.

Hett, J. M. 1971. A dynamic analysis of age in sugar maple seedlings. Ecology 52:1071-1074.

Hils, M. H., and J. L. Vankat. 1982. Species removals from a first-year old-field plant community. Ecology 63:705711.

Holmgren, M., M. Scheffer, and M. A. Huston. 1997. The interplay of facilitation and competition in plant communities. Ecology 78:1966-1973.

Holzapfel, C., and B. Mahall. 1999. Bidirectional facilitation and interference between shrubs and annuals in the Mojave Desert. Ecology 80:1747-1761.

Howard, T. G., and D. E. Goldberg. 2001. Competitive response hierarchies for different fitness components of herbaceous perennials. Ecology, in press.

Hunter, A. F., and L. W. Aarssen. 1988. Plants helping plants. Bioscience 38:34-40.

Inouye, R. S. 1980. Density-dependent germination response by seeds of desert annuals. Oecologia 46:235-238.

Jonsdottir, I. S. 1991. Effects of tiller size and population dynamics in a clonal sedge Carex bigelowii. Oikos 62:177188.

Kadmon, R. 1995. Plant competition along soil moisture gradients: a field experiment with the desert annual Stipa capensis. Journal of Ecology 83:253-262.

Lambers, H., and H. Poorter. 1992. Inherent variation in growth rate between higher plants: a search for physiological causes and ecological consequences. Advances in Ecological Research 23:187-261.

Law, R., and A. R. Watkinson. 1987. Response-surface analysis of two-species competition: an experiment on Phleum arenarium and Vulpia fasciculata. Journal of Ecology 75: 871-886.

Law, R., and A. R. Watkinson. 1989. Competition. Pages 243-284 in J. M. Cherret, editor. Ecological concepts: the contribution of ecology to an understanding of the natural world. 29th symposium of the British Ecological Society, London 1988. Blackwell Scientific Publications, Oxford, UK.

Linhart, Y. B. 1976. Density-dependent seed germination 
strategies in colonizing versus non-colonizing plant species. Journal of Ecology 64:375-380.

McMurray, M., S. H. Jenkins, and W. S. Longland. 1997. Effects of seed density on germination and establishment of a native and an introduced grass species dispersed by granivorous rodents. American Midland Naturalist 138: 322-330

McPeek, M. A., and B. L. Peckarsky. 1998. Life histories and the strengths of species interactions: combining mortality, growth, and fecundity effects. Ecology 79:867-879.

Miller, T. E. 1987. Effects of time of emergence on survival and growth in an early old-field plant community. Oecologia 72:272-278.

Miller, T. E. 1994. Direct and indirect species interactions in an early old-field plant community. American Naturalist 143: $1007-1025$.

Murray, B. R. 1998. Density-dependent germination and the role of seed leachate. Australian Journal of Ecology 23: 411-418.

Naylor, J. M., and L. A. Christie. 1956. The control of dormancy in wild oats. Pages 56-59 in National Weed Committee of Canada (Western section) Proceedings of the 10th meeting.

Newman, E. I. 1973. Competition and diversity in herbaceous vegetation. Nature 244:310-311.

Noble, J. C., A. D. Bell, and J. L. Harper. 1979. The population biology of plants with clonal growth. I. The morphology and structural demography of Carex arenaria. Journal of Ecology 67:983-1008.

Noy-Meir, I. 1973. Desert ecosystems: environment and producers. Annual Review of Ecology and Systematics 4:2551.

Osenberg, C. W., O. Sarnelle, S. D. Cooper, and R. D. Holt. 1999. Resolving ecological questions through meta-analysis: goals, metrics and models. Ecology 80:1105-1117.

Pacala, S. W., C. D. Canham, J. Saponara, J. A. Silander, Jr., R. K. Kobe, and E. Ribbens. 1996. Forest models defined by field measurements: estimation, error analysis and dynamics. Ecological Monographs 66:1-43.

Palmblad, I. G. 1968. Competition in experimental populations of weeds with emphasis on the regulation of population size. Ecology 49:26-34.

Putwain, P. D., and J. L. Harper. 1970. Studies in the dynamics of plant populations. III. The influence of associated species on populations of Rumex acetosa and $R$. acetosella L. in grassland. Journal of Ecology 58:251-264.

Sarukhán, J. 1974. Studies on plant demography: Ranunculus repens L., R. bulbosus L., and R. acris L. Journal of Ecology 62:151-177.

Sarukhán, J., and J. L. Harper. 1973. Studies on plant demography: Ranunculus repens L., $R$. bulbosus L., and $R$. acris. I. Population flux and survivorship. Journal of Ecology 61:675-716.

Schmitt, J., J. Eccleston, and D. W. Ehrhardt. 1987. Densitydependent flowering phenology, outcrossing and reproduction in Impatiens capensis. Oecologia 72:341-347.

Shaw, R. G. 1987. Density dependence in Salvia lyrata: experimental alteration of densities of established plants. Journal of Ecology 75:1049-1063.

Shaw, R. G., and A. Antonovics. 1986. Density dependence in Salvia lyrata, a herbaceous perennial: the effects of experimental alteration of seed densities. Journal of Ecology 74:797-814.

Silander, J. A., and J. Antonovics. 1982. Analysis of interspecific interactions in a coastal plant community: a perturbation approach. Nature (London) 298:557-560.
Silvertown, J., M. Franco, and E. Menges. 1996. Interpretation of elasticity matrices as an aid to the management of plant populations for conservation. Conservation Biology 10:591-597.

Silvertown, J., M. Franco, I. Pisanty, and A. Mendoza. 1993. Comparative plant demography-relative importance of life-cycle components to the finite rate of increase in woody and herbaceous perennials. Journal of Ecology 81:465476.

Sinclair, A. R. E. 1989. Population regulation in animals. Pages 197-241 in J. M. Cherrett, editor. Ecological concepts: the contribution of ecology to an understanding of the natural world. Twenty-ninth symposium of the British Ecological Society, London 1988. Blackwell Scientific, Oxford, UK.

Smith, B. H. 1983a. Demography of Floerkea proserpinacoides, a forest-floor annual. I. Density-dependent growth and mortality. Journal of Ecology 71:391-404.

Smith, B. H. 1983b. Demography of Floerkea proserpinacoides, a forest-floor annual. II. Density-dependent reproduction. Journal of Ecology 71:405-412.

Smith, B. H. 1983c. Demography of Floerkea proserpinacoides, a forest-floor annual. III. Dynamics of seed and seedling populations. Journal of Ecology 71:413-425.

Smith, T., and M. Huston. 1989. A theory of the spatial and temporal dynamics of plant communities. Vegetatio 83:4970

SPSS 1997. SYSTAT for Windows. Version 7.01. SPSS, Chicago, Illinois, USA.

Stewart-Oaten, A. 1995. Rules and judgments in statistics: three examples. Ecology 76:2001-2009.

Symonides, E. 1983. Population size regulation as a result of intra-population interactions. II. Effect of density on the growth rate, morphological diversity, and fecundity of $\mathrm{Er}$ ophila verna (L.) C. A. M. individuals. Ekologia Polska 31:883-912.

Tilman, D. 1988. Plant strategies and the dynamics and structure of plant communities. Princeton University Press, Princeton, New Jersey, USA.

Watkinson, A. R. 1980. Density-dependence in single-species populations of plants. Journal of Theoretical Biology 83: 345-357.

Watkinson, A. R. 1985. Plant responses to crowding. Pages 275-289 in J. White, editor. Studies on plant demography: a festschrift for John L. Harper. Academic Press, London, UK

Watkinson, A. R. 1997. Plant population dynamics. Pages 359-400 in M. J. Crawley, editor. Plant Ecology. Second edition. Blackwell Scientific, Oxford, UK.

Watkinson, A. R., W. M. Lonsdale, and M. H. Andrew. 1989. Modeling the population dynamics of an annual plant Sorghum nutans in the wet-dry tropics. Journal of Ecology 77:162-181.

Williamson, G. B. 1990. Allelopathy, Koch's postulates, and the neck riddle. Pages 143-162 in J. B. Grace and D. Tilman, editors. Perspectives on plant competition. Academic Press, San Diego, California, USA.

Wilson, S. D., and D. Tilman. 1991. Components of plant competition along an experimental gradient of nitrogen availability. Ecology 72:1050-1065.

Wilson, S. D., and D. Tilman. 1995. Competitive responses of eight old-field plant species in four environments. Ecology 76:1159-1180.

Wurzburger, J., and Y. Leshem. 1969. Physiological action of the germination inhibitor in the husk of Aegilops kotschyi Boiss. New Phytologist 68:337-341. 